\title{
Cellular forces during early spreading of T lymphocytes on ultra-soft substrates
}

Farah Mustapha ${ }^{1,2,3,4,5}$, Martine Pelicot-Biarnes ${ }^{1,2,3,4}$, Remy Torro ${ }^{1,2,3,4,5}$, Kheya Sengupta ${ }^{4,5, *}$,

Pierre-henri Puech ${ }^{1,2,3,4, *}$

\section{Affiliations:}

Laboratoire Adhésion et Inflammation (LAI)

${ }^{1}$ Aix Marseille University, LAI UM 61, Marseille, F-13288, France.

${ }^{2}$ Inserm, UMR_S 1067, Marseille, F-13288, France.

${ }^{3}$ CNRS, UMR 7333, Marseille, F-13288, France.

CENTURI

${ }^{4}$ Turing Centre for Living systems, Marseille, France

Centre Interdisciplinaire de Nanoscience de Marseille (CINAM)

${ }^{5}$ CNRS - AMU UMR 7325, Marseille, F-13288, France

${ }^{*}$ To whom correspondence should be addressed :

sengupta@cinam.univ-mrs.fr, pierre-henri.puech@inserm.fr 


\begin{abstract}
$\mathrm{T}$ cells use forces to read out and act on the mechanical parameters of their microenvironment, which includes antigen presenting cells (APCs). Here we explore the early interaction of T cells with an APC-mimicking ultra-soft polymer gel exhibiting physiologically relevant stiffness in the range of 350-450 $\mathrm{Pa}$. We quantify the dependence of cell spreading and stiffness on gel elasticity, and measure early time traction forces. We find that coating the surface with an antibody against the CD3 region of the TCR-complex elicits small but measurable gel deformation in the early recognition phase, which we quantify in terms of stress or energy. We show that the time evolution of the energy follows one of three distinct patterns: active fluctuation, intermittent, or sigmoidal signal. Addition of either anti-CD28 or anti-LFA1 has little impact on the total integrated energy or the maximum stress. However, the relative distribution of the energy patterns does depend on the additional ligands. Remarkably, the forces are centrifugal at very early times, and only later turn into classical in-ward pointing centripetal traction.
\end{abstract}




\section{Introduction}

$\mathrm{T}$ cells are activated when with the membrane bound $\mathrm{T}$ cell receptors (TCRs) recognize foreign antigenic peptides presented by the major histocompatibility complexes (pMHCs) of antigen presenting cells (APCs), within a small cell-cell contact area termed the immune synapse (IS) (Reichardt, Dornbach, and Gunzer 2010; Grakoui et al. 1999; Monks et al. 1998). This interaction bridges the innate and adaptive immune responses, as the activated T cells multiply and further differentiate, depending on their sub-type, into Cytotoxic $\mathrm{T}$ cells that directly kill virally infected cells and cancer cells, and Helper and Regulatory $\mathrm{T}$ cells that activate and tune the effector functions of other cells in the immune system. In either case, a given $\mathrm{T}$ cell has the formidable task of identifying a particular cognate pMHC against a very noisy environmental background of endogenous self-pMHCs, and to do so quite rapidly as to avoid any potential damage to healthy tissue. Today, an extensive body of research exists describing the biochemical signaling pathways triggered upon the pMHC-TCR interaction, however, further work is needed to unravel the precise mechanism(s) of T-cell activation (He and Bongrand 2012; Malissen and Bongrand 2015; Puech and Bongrand 2021). The formation of the IS is preceded by very dynamic processes whereby the T cell deforms and spreads over the surface of the APC, by extensively reorganizing its cytoskeleton. Such elegant observations were the first indication that physical forces may potentially play a critical role in T cell activation (B.-C. Chen et al. 2014).

Indeed, early work on tissular cells, such as fibroblasts, has demonstrated that individual cells do have the capacity to generate forces (Pelham and Wang 1997). Similar cells were shown to generate relatively large forces, transmitted through well-defined adhesion structures such as focal adhesions or focal complexes (B. Geiger and Bershadsky 2001; Solon et al. 2007; Engler et al. 2006; Elosegui-Artola et al. 2016). This body of work brought to light the relative roles of actin and myosin in force generation and transduction, as well as the existence of cross-talk with adhesion molecules, other mechanosensitive proteins and different signaling pathways, making cell mechanobiology a complex corner-stone in understanding not only adhesion and migration but virtually all aspects of cellular physiopathology (Benjamin Geiger, Spatz, and Bershadsky 2009; Schwarz and Safran 2013; Janmey et al. 2009; Vogel and Sheetz 2006; Martino et al. 2018).

Immune cells on the other hand, including T cells, do not form focal-adhesion-like structures per se but do exert or feel forces during their physiological action. The forces exerted by these cells are expected to be comparatively feeble and less localized. Nevertheless, the ability of immune cells to generate and respond to forces is at the heart of their function in a variety of situations, 
ranging from phagocytosis (Herant 2006; Vorselen et al. 2020; 2021; Jaumouillé and Waterman 2020) and stop/go signal for migration (Jannat, Dembo, and Hammer 2011; S. H. J. Kim and Hammer 2021; Huse 2017), to antigen extraction and maturation by B cells (Spillane and Tolar 2018; Kumari et al. 2019) and early activation of $\mathrm{T}$ cells (Hu and Butte 2016; Thauland et al. 2017; Klotzsch and Schütz 2013; Y. Liu et al. 2016).

Indeed, recent studies have shown that $\mathrm{T}$ cells are not only sensitive, but also responsive, to forces acting at both the molecular and cellular scale (Huse 2017; Limozin and Puech 2019; Puech and Bongrand 2021).

At the molecular scale, the modification of the kinetics of the pMHC-TCR bond under force is thought to be implicated in its ability to distinguish different peptidic antigens (Limozin and Puech 2019; Y. Chen et al. 2017). Measuring single pMHC-TCR rupture forces using Atomic Force Microscopy did not reveal any strong differences upon peptide variation (Puech et al. 2011), however, Biomembrane Force Probe experiments did identify the bond lifetime as a potential key parameter in determining the outcome of the interaction (Ju et al. 2017). It has also been proposed that pMHC-TCR bond may function as a catch bond (B. Liu et al. 2014), whereby the lifetime of the bond is prolonged upon the application of physical force; nevertheless, this point, and in particular the origin of such a complex behavior, is still a matter of debate (Limozin et al. 2019; B. Liu, Kolawole, and Evavold 2021). Even more, the geometry of the applied force has also been investigated using Optical Tweezers and Micropipettes (S. T. Kim et al. 2012; 2009), and led to the proposal that its evaluation by the cell is another important modulator of recognition.

The importance of mechanics at the cell-scale has also been demonstrated (Judokusumo et al. 2012; O'Connor et al. 2012; Wahl et al. 2019; Hivroz and Saitakis 2016; Saitakis et al. 2017), and recently emphasized by showing that immune cells, in particular APCs, possess particular mechanical features that can be modulated as a function of the inflammatory conditions (Bufi et al. 2015), and that $\mathrm{T}$ cells are capable of probing and reacting to this modulation (Judokusumo et al. 2012; O'Connor et al. 2012; Wahl et al. 2019). Interestingly, T cells have also been shown to sense resistance to forces parallel to their membrane place, thus being able to respond to ligand mobility (Dillard et al. 2014; Jankowska et al. 2018; Comrie, Babich, and Burkhardt 2015), as well as readily modulate their viscoelastic properties in response to specific signals at very short scales compared to the ones recorded for calcium fluxes, a hallmark of internal signal transduction (Zak et al. 2021).

Despite the highly detailed knowledge we have gathered thus far, it seems that the full description of cell-scale mechanosensitivity, as well as its link to molecular scales, is still far 
from being achieved.

Clearly, an important aspect of understanding cell-scale mechanosensitivity is obtaining a reliable and early measurement of forces exerted by $\mathrm{T}$ cells when contacting a cognate surface. As mentioned above, $\mathrm{T}$ cells do not exhibit focal adhesion like structures, and moreover at short contact times, the traction forces applied by leukocytes in general, and T cells in particular, are expected to be comparatively low in magnitude and deployed on small, less defined, contact zones as compared to that of large fibroblasts or epithelial cells. From a physiological point of view, $\mathrm{T}$ cells are very reactive cells and may also exist in different initial states, ranging from naive to anergized (i.e. non-reactive state). This potentially leads to force amplitude and patterns that differ even within a given cell population. This in itself portrays a challenge for quantification, analysis, and interpretation, even in hybrid in vitro systems such as cells interacting with deformable gels.

Here we use well-characterized and reproducible ultra-soft polyacrylamide gels (PAGs) of variable elasticity $(0.4-200 \mathrm{kPa})$ to quantify the stresses exerted by $\mathrm{T}$ cells during their early spreading (first 15-30 minutes). We employ Traction force microscopy (TFM, (Style et al. 2014; Lekka et al. 2021)) to follow the dynamics, magnitude, and directionality of the stresses generated during the first minutes of $T$ cell engagement with PAGs of stiffness similar to that of non-activated DCs and B cells, that is to say, about 400 Pa (Bufi et al. 2015). The cells are specifically engaged via the CD3 domain of the TCR complex, and/or the co-receptor CD28, and/or the T cell integrin LFA. To our knowledge, TFM at such a low elasticity and early interaction time is novel for $\mathrm{T}$ cells. We compare these results to those generated on stiffer, yet still biologically relevant, gels $(\approx 2 \mathrm{kPa}$, similar to activated DCs and macrophages (Bufi et al. 2015)). Our dynamic force measurements reveal new patterns of force application over time, that are modulated as a function of substrate mechanics and functionalization, and that are also impacted by the genetic manipulation of cells to introduce fluorescent reporters at the membrane or in the cytoskeleton. 


\section{Results and discussion}

\section{Characterization of soft PAA gels with and without nano-beads}

Our goal was to reach ultra-soft substrate rigidities compatible with the ones of physiological APCs (Bufi et al. 2015), laterally homogeneous on length scales similar to the $\mathrm{T}$ cell size,and in glass bottom petri dish compatible with our AFM setup and sample heating systems. We optimized the protocols readily available in literature, mainly focusing on that from (Tse and Engler 2010), to obtain thin, but thick enough, films of well-defined and reproducible rigidity (Mustapha, Sengupta, and Puech 2022). We systematically quantified the relative intra- and inter-gel variation of elasticities using AFM microindentation with soft AFM cantilevers, each decorated with a bead of a radius compatible to typical T cells size $(\sim 5-10 \mu \mathrm{m}$ in diameter, Fig. $1 \mathrm{~A}, \mathrm{~B})$.

On Fig.1, we present our measurement strategy. The typical measured thickness of the gels was $\sim 80 \mu \mathrm{m}$. Fig. $1 \mathrm{C}$ presents a typical force curve obtained while pushing (light red) then pulling (dark red) with the Hertz model fit superimposed (in green). Note that all data presented in Fig. 1C-E was obtained on bead-free gels. The pulling part of the curve shows that very little adhesion is present, allowing us to use a Hertz-like model on the pushing part for quantifying the Young modulus of the gel (the larger the Young modulus, the stiffer the gel). By laterally displacing the indenter, one can map the Young modulus to record the lateral homogeneity. Here we used beads of the same size as the T cells ( 5 to $10 \mu \mathrm{m}$ diameter) and a similar lateral spacing for the indentation zones (typically $8 \mu \mathrm{m}$ ). Such a map is shown on Fig1D for a 400Pa nominal rigidity gel. The maps revealed rather homogeneous elasticities, with a dispersion within a given gel being of the same order as the one in between samples (Fig.1E, insert is a zoom on $0.4 \mathrm{kPa}$ repeats). As such, using our refined protocol, we were able to produce gels with a very large range of well defined and reproducible rigidities (nominal $0.4 \mathrm{kPa}-200 \mathrm{kPa}$ ), encompassing the reported range for macrophages and dendritic cells at different moments of the inflammatory process $(0.4 \mathrm{kPa}-4 \mathrm{kPa}$, Fig. 1E). While cell spreading and cell elasticity measurements were done on the entire gel-elasticity range, we selected the softer gels corresponding to reported APC elasticities for TFM experiments. This also maximizes the displacement of reporter-nanobeads for feeble applied forces as expected for the early interaction of the cells with the gels (Kumari et al. 2019). We verified that these gels are elastic within our experimental margins (Suppl. Fig. 1).

Next we then characterized the very soft PAA gels when doped with fluorescent nanobeads. As reported before (Mustapha, Sengupta, and Puech 2022), a layer of nanobeads is formed close to each of the two interfaces of the gel (Fig. 1F). The typical position of the top layer, facing the cells, was found to be $\sim 2 \mu \mathrm{m}$ from the gel surface, allowing us to observe, at $40 \mathrm{x}$, the nanobeads 
and the cells simultaneously. The density of nanobeads in the upper layer was observed to be fairly homogeneous (Fig 1G), and rather high, which is an advantage for performing TFM based on PIV analysis (see Material and Methods). Typically, we had four beads in an area of $2.5 \times 2.5$ $\mu \mathrm{m}^{2}\left(16 \mathrm{x} 16 \mathrm{px}^{2}\right)$.

We observed an increase of the Young modulus of the doped gels by a factor $\sim 2$, due to the presence of the nanobeads (Fig. 1I). Since the nanobeads were washed before inclusion in the gels, this could not be attributed to modification of gel chemistry by an agent in the bead solution. We therefore concluded that at the moderate indentation forces used here, we were probing a zone close to the one dense in beads, in the vertical ' $z$ ' direction. Since we expect similar forces and therefore similar probing of depth from the cells, this apparent value of Young modulus (400Pa) was used in the TFM calculations, instead of the nominal value for bead-less gels. In addition, we note that using unwashed nanobeads makes the gels less reproducible, and also usually produces softer gels (not shown). We attributed this to the presence of chemicals (in particular sodium azide for preventing bacterial growth) which most likely perturb the polymerisation of PA. Interestingly, for the $2 \mathrm{kPa}$ gel, elasticity was only very weakly perturbed by the presence of the nanobeads (not shown).

Covalent binding of fluorescent antibodies to the gels ensured a homogeneous lateral $(\mathrm{x}, \mathrm{y})$ coating (Fig. 1H and J). The measured fluorescent signal was confined to the surface, indicating that the gels have negligible porosity. We subsequently quantified the amount of grafted antibodies using fluorescence microscopy following (Hornung et al. 2020) to be $\sim 640$ molecules/ $\mu \mathrm{m} 2$ for a $2 \mathrm{hrs}$ of incubation with a $30 \mu \mathrm{l} / \mathrm{ml}$ solution of antibody (Suppl.Fig 1 ).

As a conclusion, we revealed that, for these very soft gels, the local elasticity in the vicinity of the surface is influenced by the presence of beads over the depths that are of the order of the ones probed by the stress generated by the cells. This again underlines that the impact of any reporter molecule or other object included in a mechanosensory study needs to be carefully investigated and reported, as we have previously shown for fluorescent calcium reporters (Cazaux et al. 2016; Sadoun et al. 2021).

\section{Cell adhesion, spreading, and mechanics are modulated by PAA gels elasticity}

To quantify the effect of substrate rigidity on cell spreading and mechanics, we seeded Lifeact-GFP transfected cells on nanobead-free gels of various rigidities, which were surface grafted with aCD3. The apparent spreading area of the cells was quantified, at a given time point, using fluorescence microscopy. In separate experiments, their young modulus was measured by 
indenting them with a moderate force by AFM, leading to depths of indentation $<1 \mu \mathrm{m}$, which represents $\sim<10 \%$ of cell diameter.

Fig.2A shows a sketch of the spreading experiments. The blue band depicts the depth at which we set the focus by detecting small defects or dust-particles on the gel surface by transmission microscopy. A typical cell fluorescence image is shown on Fig. 2B, after 20 min of sedimentation and contact. We made sure that the cells we evaluated were mostly adherent by gently tapping on the microscope base and observing their immobility. After image acquisition, we delineated using Fiji freehand selection tool, the contour of the cell to extract the apparent cell (contact) area (Fig. 2C). The measured area of the cells was widely distributed, and the median values were weakly, but significantly, dependent on substrate elasticity. We observed that the cells have a tendency to spread, on average, more on the softer, more physiological substrate. This observation is in good agreement with (Wahl et al. 2019). However, one should note that here we report the apparent area whereas it would be more rigorous to measure the contact area using a surface technique like reflection interference or total reflection microscopy (Wahl et al. 2019). However, PAA gels are not amenable to either technique, since their index is close to that of the medium, and they have a non-negligible thickness.

In separate experiments, the elasticity of the cells was measured after they interacted with a surface for $20 \mathrm{~min}$. For the measurements, the AFM head has to be lowered towards the surface through the medium using stepper motors so that the cantilever can be close to the surface (Fig. 2D, E). The resultant mechanical perturbations lead to the lifting of almost all cells from the substrate for the softest gels. In this case, reproducible indentations were impossible to perform: cells appeared to slide away from the AFM cantilever bead tip and the indentation force curves looked distorted. We therefore cannot report a reliable value for this case (Fig. 2F). In all the other cases, cells were not visibly perturbed by the approach of the AFM head, and the measured Young modulus is typical for Jurkat cell line and other lymphocytes (Cazaux et al. 2016; Sadoun et al. 2021; Zak et al. 2021). The value of the Young modulus does not show strong variation with substrate elasticity, except for the harder gels (Fig. 2F), which could indicate that the deformation of the gel under the cells can be neglected (Rheinlaender et al. 2020). The order of magnitude of the cell Young modulus, when spread on our aCD3 gels, should then be taken as the average of the ones measured over the two "softer" gels (namely 2 and $20 \mathrm{kPa}$ here), leading to a value $\sim 100 \mathrm{~Pa}$. On the stiffer gels that do not mimic per se any relevant APC (Bufi et al. 2015), the situation of the spreading could be very different, similar to what we reported for the effect of relaxing any shape constraint (Sadoun et al. 2021). Nevertheless, one has to note that the order of magnitude of the Young modulus stays very close to the one usually reported as it is 
here $(\sim 100 \mathrm{~Pa})$, far more than what has been reported to be measured using dynamic AFM modes (> 10kPa, (Jung et al. 2021)) which strengthen our conclusion above.

In the first part of this work, we produced well controlled PAA gels and laterally characterized their mechanical properties using indentation maps in AFM with moderate forces, on scales that are compatible with immune cell dimensions. These properties are homogeneous, tunable over a large range of elasticities, and down to physiological antigen presenting cell ones (Bufi et al. 2015). Such approaches are consistent with the work of others, on B lymphocytes and neutrophils in particular, in terms of gel or substrate elasticity (Kumari et al. 2019; 2020; Henry et al. 2015). Nevertheless, we used antibody-only substrate decorations, and softer substrates as compared to previous reports on Jurkat cells, where polylysine was used as an underlying layer, which likely increased the spreading of the cells via non-specific, charge-based interactions (Hui et al. 2015). By doing so, we were looking to compare situations where only specific signals, with a non specific interaction background as low and controlled as possible, were made available to the cells as in (Dillard et al. 2014; Wahl et al. 2019). As such, potential smaller spreading areas were expected, together with reduced stresses as when superimposed with non specific eg. electrostatic interactions, since the PAA gels are intrinsically non-fouling substrates, ie. essentially not adherent for cells in general, which applies to T cells (not shown here, but see below for IgG2a coated gels).

\section{Early spreading on very soft gels reveals three distinct force application behavior}

On Fig. 3A, we summarize our strategy for performing traction force microscopy with open-source tools (Mustapha, Sengupta, and Puech 2022). To capture the first moments of recognition, image acquisition is started before seeding cells, which allows us to use the first frame of our movies as a reliable reference for the unperturbed state of the nanobeads in the gel. Taking simultaneous images of the cells (fluorescence or transmission) and the nanobeads (fluorescence) (Fig 3B), we tracked the changes in the position of the nanobeads under a given cell. This was done by calculating the displacement of the beads at each time point using PIV (Fig. 3C, normalized). The first frame was used as a reference, and sample drift was quantified and compensated for. By applying FTTC, we were able to obtain maps of stress vectors, from which we plotted maps of stress-norms for given time points, in order to observe lateral distribution and magnitude of the stress (Fig. 3D). We summarized these series of snap-shots of stress maps into graphs that track, as a function of time, either the sum of the stress-norms over the whole image, (Fig. 3E top, 'stress-sum' in $\mathrm{Pa}$ ), or the scalar product of the displacements and forces at each reconstituted pixel (Fig. 3E bottom, 'Energy' in J). The latter was offset to zero from a baseline, whose value appeared to be robust between experiments (not shown here), and 
was defined using the first few time points recorded before the arrival of a cell. In the following discussion, we shall focus on the time dependent evolution of the Energy (time-energy curves), and the peak value of the stress-sum (Max Stress Sum). The regularization factor, always required for TFM quantification, was optimized for our experiments (Suppl. Fig. 2) and set to the empirically obtained value of 9E-10 (Mustapha, Sengupta, and Puech 2022), which is coherent with previous reports using the same data processing procedure (Tseng et al. 2012).

Experimentally, we first verified that no significant nanobead motion was detected on IgG2a (isotype control) coated gels. In contrast, all cells, with some rare exceptions, caused small but visible nanobead displacements when the substrate was coated with the activating antibody aCD3, which was used either alone, or with aCD28 against the coreceptor CD28 or with aCD11a that targets the integrin LFA1. This demonstrates that the cell-gel interaction is highly specific, and that no non-specific interaction occurs with the PAA, decorated or not with a non relevant antibody.

Next we focused on gels that were functionalized with aCD3. Interestingly, the time evolution of the energy shows three distinct and typical patterns (Fig. 4A). In the first case, which we call sigmoidal signal, the energy remains low for a whole and then jumps to a value whose magnitude is large compared to the small fluctuations visible before the arrival of the cell, and stays at this value during the remaining entire time (15 minutes) of experiment. In the second case, the energy slowly climbs to a high magnitude (comparable to sigmoidal signal) but then decreases again. We call this the intermittent signal. Finally, the third case is where the signal fluctuates around a low value which is nevertheless higher than the noise detected before arrival of cells (see below). We call this the active fluctuation case. To our knowledge, the time evolution of traction forces was never followed during early spreading events, especially for leukocytes, and such temporal patterns were never reported before.

The three types of time-energy profiles were seen also in cases where either aCD28 or aCD11a was present in addition to aCD3. However, in case of IgG2a, a small noisy fluctuating signal was obtained, which was indistinguishable from the noise before seeding of the cells.

To ascertain the 'active fluctuation' case was indeed not noise, we analyzed the standard-deviation of the fluctuating energy curves obtained from under cells seeded on IgG2a and the aCD3 combinations and compared them to cell-free zones of aCD3 coated gels, since the last can can be considered to be a robust readout of the noise level of the measurements. Interestingly, we observed that in the control case, as for IgG2a, the standard deviation did not 
vary between before cell seeding or after $20 \mathrm{sec}$ of cell introduction, while it was significantly increased for the aCD3 combinations (Fig. 4B). The $20 \mathrm{sec}$ time cut-off corresponds to the typical time needed for the cells to sediment on the gel. We can therefore distinguish the signal on IgG2a that we qualify as "passive noise" and the aCD3 combinations that we call "active fluctuations", as stated above. The observation of only passive, noise-like fluctuations under cells on IgG2a confirms our previous conclusion that, as expected, no interaction occurs between the cell and the surface on the isotype control.

We note that the fluctuations we observed are reminiscent of the tiptoeing of cells above substrates before the cells make any decision to spread or not (Pierres et al. 2008; Brodovitch, Bongrand, and Pierres 2013). Unfortunately, due to the loss of lateral resolution imposed by the PIV/FTTC methodology, we could not resolve the real lateral size of the zones where these oscillations were present. Most likely, the active fluctuations could arise due to active dynamics of microvilli, the tip of which is meant to be a mechanosensitive probe of substrates (Brodovitch, Bongrand, and Pierres 2013) which can even penetrate the target cell to probe its mechanics while increasing the effective contact area of the functional structures (H.-R. Kim et al. 2018; Sage et al. 2012).

Quantifying the occurrence of the three types of time-energy curves, we observed that the relative frequency of each type depends on the molecular coating of the gel (Fig. 4C). Intermittent and sigmoid signals, with large magnitude, dominate on aCD3 and aCD3/aCD28 coatings, whereas active fluctuations, of relatively smaller magnitude, are significantly present for the aCD3/aCD11a coating. As already mentioned, cells on IgG2a coating only presented very small magnitude, passive and noisy fluctuations.

Ignoring for the moment the various time-energy curve types, we pooled the entire population of cells for each antibody case. The Max Stress Sum (Fig. 4D) and the integrated energy (Fig. 4E) were, as expected, significantly higher for the aCD3 combinations than for the IgG2a control. Note that for the integrated energy, slightly negative values were sometimes obtained for the fluctuations (both passive and active) due to the baseline correction which did not take the slow decreases of the average signal observed on certain curves into account. Of note, we did not observe on the pooled populations (Fig. 4D,E) a strong dependence of either Max Stress Sum or integrated energy on the molecular details of the substrate for the activating substrates. Moreover, we observed that the time when the maximal force peak occurs was delayed for the aCD3 combinations compared to IgG2a (not shown), coherent with the typical times needed for the cells to be activated (Sadoun et al. 2021). 
Intermittent signals were for each substrate, as expected, of lower integrated energy than for sigmoid ones, aCD3/aCD11a being the lowest, while aCD3 and aCD3/aCD28 were of a similar and higher magnitude. Nethertheless, for these latter, the medians showed the same tendency for the two substrate types, aCD3 being slightly higher than aCD3/aCD28. This not so strong role of aCD28 together with aCD3 is reminiscent of our recent observation that aCD28 did not strongly influence the spread area of the same cell line on soft substrates (Wahl et al. 2019), while it could be different for primary cells (Judokusumo et al. 2012).

As a consequence, we can hypothesize that the modulations we observed on the integrated energies when pooling the data for all curves is a combination of the magnitude of the TFM characteristic signals we detected and of the relative occurrence of the fluctuating vs. intermittent vs. sigmoid behaviors. We can therefore propose that the substrate type dictates not only the morphology but also the magnitude of the deplacements and resulting stresses generated for the early recognition of a given substrate.

Our data, per se, do not push us to link the observed difference in both the relative fractions and integrated energies of the three energy morphologies with the cells being in different pre-activation states, since we used the Jurkat cell line as model T lymphocytes. It much more reveals the relative effects of substrate decoration on their early recognition by these cells. Aside, such variability of behavior has rarely, if ever, been reported in literature, but could be present in any TFM-like experiment when the processes are occurring early in the interaction with the substrates, followed over time and not at a single, later time point, which may complexify the description and understanding of the data.

We then compared in coupled experiments the behaviors of the same Lifeact cells on CD3 coated substrates with a Young modulus of $\sim 400 \mathrm{~Pa}$ vs $\sim 2 \mathrm{kPa}$. Interestingly, we observed that the fraction of intermittent morphology was dominating the more rigid gel (Fig. 1G). Consequently, the pooled maximal stress sum and integrated energy were lower in this later case(Fig. $4 \mathrm{H}$ and I). The separation of the integrated energies per morphology is shown on Fig. 4J for completude. These observations underline the necessity of using very soft gels, and show why using typical "soft" gels in the range of $2-5 \mathrm{kPa}$ as for adherent cells is surely not optimal: the intermittent population may be missed depending on the moment where the exploration of the samples are performed, leading to the false impression that very little cells are indeed pulling / pushing on the gels, if any. 


\section{Stress vectors are initially pointing outwards while the cell spreads, then reverse their direction at longer times}

When extending the observation duration from 15 to $30 \mathrm{~min}$, we observed that the cells may change their behavior over time. Below $15 \mathrm{~min}$, they mainly spread, and as consequence the beads below them displace outward (Suppl. Fig. 4A), the resulting stresses pointing also outwards (Suppl. Fig. 4B). The number of PIV calculated pixels exhibiting a displacement above the noise level detected outside the zone below the cells increased with the accumulated energy (Suppl. Fig. 4C). For longer times, cells start to pull, potentially retract, and bead displacements will point inward, with the resulting stress vectors pointing inwards. Eventually, as exemplified in Suppl. Fig. 4, the cell may stop interacting, or at least, to generate detectable beads motions. This is coherent with the observations made with soft micropillar experiments with different cellular systems (Bashour et al. 2014; Henry et al. 2015; Jin et al. 2019) and with micro-mechanical manipulations (Husson et al. 2011; Sawicka et al. 2017; Hu and Butte 2016; Thauland et al. 2017). Such a contraction at later times during a contact is reminiscent of typical observation for activating $\mathrm{T}$ cells: they stop migrating first, and then change shape by rounding while becoming polarized; when micro-manipulated against an activating bead or an AFM cantilever, they start to push, then pull on the object.

\section{Fluorescent reporters may modulate TFM energy patterns}

In the bulk of this study, Jurkat cells transfected with a cytoskeletal fluorescent reporter (Lifeact-GFP) were used. The use of fluorescent cells in TFM eases their detection and allows the use of multiband filter sets and diodes for changing the illumination without introducing any mechanical action on the microscope which may perturb the lateral/vertical position of the sample compared to the control image. However, though often these labelings are used as simple reporters, without verifying their impact on the biophysical or even biochemical properties of interest, they may in fact impact the final readout.

To assess the possible impact of using genetically modified cells, we compared the behavior of Jurkat WT (non-fluorescent, carrier cell line), Jurkat transfected with a membrane fluorescent construct (Lck-GFP) or with a cytoskeletal fluorescent construct (Lifeact-GFP, which had been used for the rest of our study). The cells where allowed to interact with aCD3 coated 400Pa PAA gels. The first observation was that the WT cells and the two modified cell lines exhibited the same type of shapes in energy vs. time curves. Nevertheless, their relative proportions varied depending on the cell type, from having the three populations in Jurkat Lck-GFP to only two in the Jurkat Lifeact-GFP and WT cases (Fig. 5A). Thus, in the Lck-GFP case, the intermittent 
behavior dominates, while for WT it is the sigmoid one. The behavior of Lifeact-GFP cells is close to that of the WT.

Even if no significant difference is detected in either the pooled maximum stress (FIg. 5B) or integrated energy (Fig. 5C), trends do appear. The Lifeact-GFP variant does have a lower median value of maximal stress than that of the WT, coherent with the impact of intercalating a dye in the actin cytoskeleton, which may impair its capacity to exert local forces. Nethertheless, when considering the integrated energy, the signals which are present are more of a long lasting morphology for the Lifeact-GFP, leading to larger values. Interestingly, the Lck-GFP variant, which is often used as a simple membrane reporter, appears to behave more like the WT case for the max stress sum, since its cytoskeleton is not affected by the labeling, but shows strong modulations of the energy signal morphologies, towards short lived or only fluctuating ones, and very few sustained, sigmoid signals : this results in a large dispersion of the energies, with very low values and very high ones.

The two variants then show a visible difference compared to WT cells. When separating the integrated energy along the different signal types, the spreading of the data leads us to conclude that for this parameter, the median data was not strongly influenced by the cell type, on aCD3 (Fig. 5D). As such, we may propose that the introduction of the fluorescent reporters may indeed have a subtle impact on the local capacities of cells to exert forces, but the major effect is on the capability to add up these forces to build up consequent stress signals over an early time frame. The absence of fluctuating signals for Lifeact-GFP tagged cells in this set of data may indicate that they potentially cannot exert small forces, while for Lck-GFP cells, the membrane modification creates something defavorable to large and long lasting signals (see Fig. 5D where intermittent low integrated energy cells are present, pointing towards the existence of short-lived transitory events).

As a matter of fact, the large dispersion we observe also underlines the possibility for the expression level of the two constructs to play a role on the stress levels and resulting morphologies of energy curves. Further experiments, eg. using scanning confocal microscopy to quantify the entire cell fluorescence level as a reporter of expression of a given reporter, together with obtaining sub populations with clearly separated fluorescence levels by cell sorting, will be needed to clarify that very precise point.

The fact that stresses and energies morphologies were modified for Lifeact-GFP cells as a comparison to WT cells, in our experiments, is well in line with the observations that Lifeact is 
not a simple reporter and that its expression can deeply affect the cell mechanics and biophysical responses as reported recently (Flores et al. 2019; Sliogeryte et al. 2016).

As a summary, we observed here the existence of differences in behavior due to labeling different compartments of the cells that have a strong implication either in cell contact to the substrate and its organization (the membrane), or the forces that can be exerted via ligand/receptor interactions (the actin cytoskeleton), pointing to the necessity of being careful when using labeled cells as surrogates of WT ones, in particular when performing single cell based biophysical assays. Again, as already discussed above, the introduction of a modification such as here the expression of a marker, which in many studies is thought to be benign and the modified cells considered to be faithful reporters of the WT cell line, may have profound effects in the case of mechano-transduction studies with very sensitive cells such as lymphocytes (Cazaux et al. 2016; Sadoun et al. 2021). As such, these modifications that are often used to observe cell position of shape may modify their initial state and initial response upon activation, as exemplified here with micromechanical measurements over time. Since we observe such effects on a cell line that is considered by many as a robust model for $\mathrm{T}$ cells, we raise the pitfall that such effects could be more important on primary cells, which may have a different, more subtle, activation history. 


\section{Conclusion}

We presented traction force microscopy experiments with well-characterized, ultra-soft, poly acrylamide gels. Using open source software solutions, we quantified the early stresses that model T lymphocytes of the Jurkat cell line applied when interacting with aCD3, or aCD3 in combination with an antibody against a coreceptor (aCD28) or an adhesion molecule (aCD11a). We observed that the patterns of time-evolution of stress and energy can be classified into three distinct categories, the frequency of each depends on the specific antibody or antibodies used to coat the gel. One of these morphologies consists of enhanced fluctuations as compared to controls, reminiscent of cells tiptoeing on substrates before taking a decision to spread or not, as reported by others. The two other categories were an intermittent signal, which grows then disappears in the 15 min observation frame, and a sigmoid signal which, once started, lasts until the end of the experiment, the cell reaching a kind of steady state in stress application.

The distribution of the categories as well as the magnitude of stress or energy are affected concomitantly by the molecular details of the coating of the gel surface. Also, we demonstrated that the ultra-soft gels were needed to detect cellular action; slightly stiffer gels resulted in mainly transient signals which are very prone to be missed by the experimentalist, depending on the time frame of the observation or the sensibility of the method in use.

When extending the observation windows to longer times, we observed that the stress vectors point outwardly when the cell spreads but often reverse direction at longer times, with the cells starting to pull on the substrate. This was coherent with reports on neutrophils by others.

Importantly, we observed modulations of the behavior, in terms of time-energy morphologies as well as magnitudes, when using variants of the Jurkat cell line, expressing a membrane or cytoskeletal reporter. We highlighted the fact that such modifications may have a profound and crucial impact on cell mechanotransduction, in particular in the early moments of the cell's interaction with a target surface, potentially even more if it is a real APC, even if such cellular modifications are often thought to be benign and used to facilitate imaging of certain cellular compartments or organizations.

Overall, here we reveal that at early times, and on ultra-soft gels of physiological stiffness, spreading $\mathrm{T}$ cells exert forces in centripetal, rather than centrifugal, direction, and that such forces are applied in three distinct time patterns. Our results provide a new insight into early stages of mechanotransduction of lymphocytes. 


\section{Material and methods}

Cell line, culture and modifications Human Jurkat T cells (clone E6-1, ATCC TIB-152), as a model for lymphocytes, were obtained from ATCC. Cells were counted and cultured three times a week, and their viability assessed by the use of Trypan Blue labeling. The cell culture medium (RPMI 1640) and complements (10\% FBS, 1\% Hepes 1M, 1\% Glutamax, 1\% Pen/Strep) were obtained from Gibco (Life technologies). Cells were monthly tested for the presence of mycoplasma.

Cell transfection \& cytometry LifeActGFP transfected Jurkat was obtained in the following manner: Lentivirus expressing LifeAct-GFP were produced in HEK 293T cells by cotransfecting the lentiviral plasmids pLenti.PGK.LifeAct-GFP.W (a gift from Rusty Lansford, Addgene plasmid \#51010; Watertown, MA) with psPAX2 and pMD2. G (a gift from Didier Trono, Addgene plasmid \#12260 and \#12259). Jurkat cells were transduced by spinoculation of virus using polybrene. The expression of LifeAct-GFP was controlled by flow cytometry using LSRFortessa X20 (BD Biosciences, Franklin Lakes, NJ). Cells expressing high levels of Life-Act GFP were sorted with BD FACSMelody cell sorter (BD Biosciences, Franklin Lakes, NJ).

Lck-GFP transfected Jurkat was obtained thus: Jurkat cells were electroporated with $1 \mu \mathrm{g}$ of DNA plasmid pcDNA3.1_mLck_GFP (produced in the lab, AM Lellouch) with Nucleofector $2 \mathrm{~b}$ device (Lonza), and selected by antibiotic G418. The expression of Lck-GFP was controlled by flow cytometry using LSRFortessa X20 (BD Biosciences, Franklin Lakes, NJ). Cells expressing high levels of mLck-GFP were sorted with BD FACSMelody cell sorter (BD Biosciences, Franklin Lakes, NJ).

Fabrication and Functionalization of Polyacrylamide gels PAGs were casted between APTES/Gluteraldehyde treated glass-bottom petri dishes (FD35-100, World Precision Instruments) and cholo-silanized glass coverslips (12mm glass coverslips, Fischer Scientific). The detailed procedure can be found in a companion protocol (Mustapha, Sengupta, and Puech 2022). Hereafter, we give the main reactants and directions .

Solutions of acrylamide (40\% wt/vol, A4058, Sigma) and N, N-methylene-bis-acrylamide (BIS, 2\% wt/vol, M1533, Sigma) were mixed with PBS to obtain: (i) 3\% acrylamide and $0.06 \%$ BIS (for a stiffness of $0.4 \mathrm{kPa}$ ), (ii) $3 \%$ acrylamide and $0.1 \%$ BIS (for a stiffness of $1 \mathrm{kPa}$ ), (iii) $4 \%$ acrylamide and $0.1 \%$ BIS (for a stiffness of $2 \mathrm{kPa}$ ), (iv) 10\% acrylamide and $0.225 \%$ BIS (for a stiffness of $20 \mathrm{kPa}$ ), and (v) 10\% acrylamide and 10\% BIS (for a stiffness of $200 \mathrm{kPa}$ ). To these formulations, $0.7 \%$ of orange fluorescent beads $(0.2 \mu \mathrm{m}$, carboxylate modified, F8809, Thermo Fisher) was incorporated. 
Crosslinking was initiated through the addition of $1 \%$ ammonium persulfate (A3678, Sigma) and $0.1 \%$ Tetramethylethylenediamine (T7024, Sigma). The entire assembly was then turned upside down (to allow the beads to move closer to the surface) and left to polymerize at $4^{\circ} \mathrm{C}$. After $1 \mathrm{hr}$, the petri dishes were immersed in PBS for $20 \mathrm{~min}$ and the top coverslips were carefully peeled off using a needle-tip.

The obtained gels were then stored overnight in PBS at $4^{\circ} \mathrm{C}$ and used the day after fabrication to ensure reproducible polymerization. The thickness of the obtained gels was measured to be typically $\simeq 80 \mu \mathrm{m}$, using a motorized inverted microscope.

Prior to experimentation, antibodies of choice were covalently attached to the surface of the gels using the photoactivatable heterobifunctional reagent sulfo-SANPAH (sulfosuccinimidyl 6 (4-azido-2-nitrophenyl-amino) hexanoate, 803332, Sigma). Briefly, the PBS was drained off the surface of the PAGs and $200 \mu \mathrm{l}$ of sulfo-SANPAH (1 mM in $50 \mathrm{mM}$ HEPES, pH 8.5) was applied. The surface of each gel was then exposed to a $365 \mathrm{~nm} \mathrm{UV} \mathrm{radiation} \mathrm{for} 2 \mathrm{~min}$ at $100 \%$ power in a UV-KUB 2 oven. The darkened sulfo-SANPAH solution was rinsed off using PBS and the photoactivation procedure was repeated a second time. Once the photoactivation was done, the gels were immediately incubated with anti-CD3 (OKT3, 14-0037-82, Thermo Fisher), anti-CD28 (14-0289-82, Thermo Fisher), anti-LFA-1 (14-0119-82, Thermo Fisher), anti-IgG2a (14-4724-85, Thermo Fisher) or a 1:1 combination of anti-CD3 and CD-28 or anti-CD3 and anti-LFA1-1, always to a final concentration of $30 \mu \mathrm{g} \cdot \mathrm{ml}^{-1}$ each and for $2 \mathrm{hrs}$ at room temperature. After $2 \mathrm{hrs}$, the gels were rinsed 3 times with PBS and the petri dishes were transferred to the microscope holder, pre-heated to $37^{\circ} \mathrm{C}$, for imaging.

Fluorescence quantification of antibody density Alexa Fluor 488 conjugated anti-human CD3 OKT3 (eBioscience by Thermo Fisher Scientific) antibody was used for the quantification of polyacrylamide gel coatings. A bulk calibration data was initially set up by measuring the fluorescence intensity of $41-\mu \mathrm{m}$-thick channels passivated with $1 \%$ Pluronic F127 (Sigma-Aldrich) and filled with antibody solutions at concentrations of $3.75,7.5,15$, and 30 $\mu \mathrm{g} \cdot \mathrm{mL}^{-1}$. In parallel, polyacrylamide gels were coated with $30 \mu \mathrm{g} \cdot \mathrm{mL}^{-1}$ of the anti-human CD3 OKT3 Alexa Fluor 488 antibody for 2 hrs at room temperature, and then imaged using the same microscope configuration as for the channels. Images were then analyzed by Fiji software and the average fluorescence intensity at three different positions was converted into surface density using the bulk calibration following (Hornung et al. 2020).

AFM set-up The set-up has been described in previous reports (Puech et al. 2011; Cazaux et al. 2016; Sadoun et al. 2021). It consists of an AFM head (Nanowizard I, JPK Instruments, Berlin) 
mounted on an inverted microscope (Zeiss Axiovert 200). The AFM head uses a $15 \mu \mathrm{m}$ z-range linearised piezoelectric scanner for motion and an infrared laser for detection. The set-up sits on an active damping table (Halcyonics). AFM measurements were performed in closed loop, constant height feedback mode. Bruker MLCT-UC cantilevers, which are not gold coated, hence less sensitive to thermal drift (Cazaux et al. 2016) were used ; glass beads (5 $\mu \mathrm{m}$ or $10 \mu \mathrm{m}$ in diameter, silica beads from Kisker Biotech $\mathrm{GmbH}$, larger than cantilever tip) were glued at their extremity using micropipette micromanipulation and UV optical glue (OP-29, Dymax) cured in a UV oven (10 min at maximal power , BioForce Nanosciences). To reduce adhesion to the gels, decorated cantilevers were passivated with 2\% Pluronic F127 (in Milli-Q water) for 30 min at $4^{\circ} \mathrm{C}$. Alternatively to MLCT-UC, SAA-HPI cantilevers (6 $\mu \mathrm{m}$ in diameter) were used without passivation since they proved experimentally to have a very small adhesion to gels or cells (not shown). The sensitivity of the optical lever system was calibrated on a glass substrate, in PBS at $37^{\circ} \mathrm{C}$ temp, together with the cantilever spring constant (by using the thermal noise method (Butt and Jaschke 1995), using JPK SPM software routines (JPK Instrument)) at the start of each experiment. The calibration procedure for each cantilever was repeated three times to rule out possible errors and spring constants were found to be consistently close to the manufacturer's nominal values.

The inverted microscope was equipped with 10x (used for laser alignment) and 40xNA0.9 (used for tip positioning and TFM measurements) objectives and a CoolSnap HQ2 camera (Photometrics). Bright field images were used to select the zone of interest on the gels. Images were obtained through either Zen software (Zeiss) or $\mu$ Manager (A. Edelstein et al. 2010; A. D. Edelstein et al. 2014). A Petri Dish Heater module (JPK Instruments) allows setting the temperature at the desired value, with a stability of a fraction of a degree over hours.

Gels and $\mathbf{T}$ cell mechanics using AFM First, the AFM cotelever bearing the bead was positioned above a selected region of the gel or on the center of an adhered cell. The maximal force to be applied was set at $2000 \mathrm{pN}$ for gels and $500 \mathrm{pN}$ for cells (leading to indentation depths of the order of one $\mu \mathrm{m}$ for cells) using a contact duration of $0 \mathrm{sec}$. If not stated explicitly, the speed of pressing and pulling was $2 \mu \mathrm{m} . \mathrm{s}^{-1}$, with an imposed maximal displacement of $7 \mu \mathrm{m}$. Then, either (i) a single force curve or a laterally resolved map (of 48x48 $\mu \mathrm{m} 2=6 \times 6$ zones, each corresponding roughly to the size of a single $\mathrm{T}$ cell) was obtained and repeated on several zones of the gels (up to 5 maps at 5 locations for a given gel) or (ii) a single or up to 5 force curves were recorded for each adhered T cell tested. Data was typically recorded at $2048 \mathrm{~Hz}$.

For determination of the Young modulus for $\mathrm{T}$ cells, each experimental force curve was examined by eye (to reject evident "bad" curves) and processed with the "Hertz model 
procedure" for a spherical tip included in JPK DP software (JPK Instruments), with the hypothesis that the cell behaves as an incompressible material $(v \sim 0.5)$. Here, only a subset of the entire force span (from the baseline to the maximal contact force) was fitted : for cells we chose to fit over $0.5 \mu \mathrm{m}$ of indentation to minimize contributions from the nucleus (Sadoun et al. 2021). Young modulus were found to be coherent with published ones for $T$ cells specifically and immune cells in general (Cazaux et al. 2016; Zak et al. 2021; Sadoun et al. 2021; Bufi et al. 2015).

For the gels, the JPK-DP software was used to convert the (compressed) force curves to text files and remove bad curves as detected by the experimentalist eye if needed. They were then batch processed using an in-house Python script similar to JPK-DP fitting procedures. Young modulus maps are then rebuilt together with histograms. We verified that the values obtained by this method are in good agreement with the ones of the manual processing using JPK-DP (the difference was observed to be less than $2 \%$ in absolute value (not shown)).

For evaluating the visco-elasticity of the gels, experiments were performed with varying the speed of the indentation between 0.1 and $10 \mu \mathrm{m} . \mathrm{s}^{-1}$. It is expected that if the Young modulus is largely not dependent on speed, then the material can be considered as mainly elastic for the range of speeds/frequencies tested.

A median value per gel or cell was then calculated and tabulated in each condition. We validated this way of pooling the data experimentally since no obvious correlation between the Young modulus and the force curve number (corresponding to the « mechanical history » of the cell or gel) was observed (not shown).

All experiments were performed at $37^{\circ} \mathrm{C}$.

T cell spreading experiments After the gels were fabricated and functionalized as described above, they were then transferred to the pre-heated epi-fluorescence microscope (described below) and left to equilibrate at $37^{\circ} \mathrm{C}$ for approximately $20 \mathrm{~min}$ before the Jurkat Lifeact-GFP cells were added. The cells were left to interact with the gels for 20 min before image acquisition started. The system was focused just above the gel surface (Fig. 2A). The images were captured through Zen software (Zeiss), and the imaging parameters were set to $25 \%$ excitation power, $100 \mathrm{~ms}$ exposure time for the GFP-labeled cells (488 nm). The obtained images were processed using Fijil/ImageJ (Schindelin et al. 2012), as shown on Fig. 2B, by delineating the contour of the cells to quantify the apparent cell area.

TFM set-up and experiments The optical microscope set-up described above (for the AFM) was used, with a 40xNA0.9 air objective and a CoolSnap HQ2 camera (Photometrics). The 
microscope was also equipped with a LED illumination system (Colibri 2, Zeiss) and suitable filter sets (Cazaux et al. 2016) for fluorescence imaging, as well as the Petri Dish Heater module (JPK Instruments) for experimentation at $37^{\circ} \mathrm{C}$. To measure the traction forces generated by Jurkat $\mathrm{T}$ cells, movies of live cells and fluorescent beads were acquired typically every 5 sec during $\mathrm{T}$ cell spreading for $15 \mathrm{~min}$ in phase contrast for the WT Jurkat T cells, in the $488 \mathrm{~nm}$ channel for the GFP-labeled Jurkat T cells, and in the $555 \mathrm{~nm}$ channel for the orange/red beads. For some movies, the duration was extended to $30 \mathrm{~min}$ and/or the time between frames set to $2.5 \mathrm{sec}$.

The polyacrylamide gels were mounted on the microscope and left to equilibrate at $37^{\circ} \mathrm{C}$ for approximately $20 \mathrm{~min}$ before the cells were added. Beads were brought into focus. Note that since the layer of microspheres is only a couple of microns beneath the gel surface (due to the flipping of the gel during the polymerization step above), the cells can still be easily seen and tracked while the focus is set on the bead layer. Image acquisition started a few seconds before cell addition, allowing us to obtain the relaxed state of the gel without the need for cell detachment using trypsin.

The movies were captured through Zen software (Zeiss), and the imaging parameters were set to: $20 \mathrm{~ms}$ exposure time for the non-labeled cells (phase contrast), 25\% excitation power 100 ms exposure time for the GFP-labeled cells (488 nm), and 50\% excitation power $200 \mathrm{~ms}$ exposure time for the orange beads ( $555 \mathrm{~nm}$ ) (Cazaux et al. 2016).

Traction Force Microscopy Image sequences of the fluorescent beads were first aligned to correct experimental drift by first extracting the trajectories of the beads on the full field images using the ImageJ "TrackMate" plugin, and then utilizing the obtained trajectories to align the images with the help of the following in-house Python 3.8 Jupyter Notebook https://github.com/remyeltorro/SPTAlign. $128 \times 128 \mathrm{px}^{2}$ (equivalent to $20 \mathrm{x} 20 \mu \mathrm{m} 2$ ) regions of interest were then selected and cropped out using ImageJ's ROI 1-click tool and the MultiCrop macro (https://github.com/phpuech/TFM) respectively. The displacement fields in the selected regions were subsequently calculated using the Image "PIV" plugin (https://sites.google.com/site/qingzongtseng/piv ; give the ref of the PNAS paper from QT), specifically the Advanced Iterative PIV option. The following parameters were set for the iterations: IW1= 64 SW1 128 VS1= 32, IW2= 32 SW2= 64 VS2 $=16, I W 3=16$ SW3 $=32$ VS3= 8 (where IW: Interrogation window, SW: Search window, VS: Vector spacing) and a correlation threshold of 0.6. The resulting final grid size for the displacement field was $\sim 2.5 \times 2.5 \mu \mathrm{m}^{2}$, with an average of four beads per interrogation window. Then the traction stress fields were reconstructed using the Fiji "FTTC" plugin (https://sites.google.com/site/qingzongtseng/tfm). 
The regularization parameter was set at $9 \times 10^{-10}$ for all traction stress reconstructions. Since the ImageJ "PIV" and "FTTC" Plugins only process two images at a time and our experimental data consists of movies (made up of $\approx 200$ frames), we wrote a function to consecutively run the two plugins over the full length image sequences of all the selected regions, always taking the first frame in each segment as the reference frame (https://github.com/phpuech/TFM). From this data, the sum of stress moduli, the stored energy as defined in (Butler et al. 2002) and the integrated energy over time (after a baseline correction for the beginning of the curve) were calculated and plotted using Python macros (https://github.com/phpuech/TFM). We described the entire detailed procedure in a recently published protocol (Mustapha, Sengupta, and Puech 2022).

Data processing, visualization and statistics AFM data was processed partly using JPK-DP (JPK Instruments, Berlin) and partly using an in-house Python 3.8 set of functions to quantify and represent the Young modulus maps and distributions.

TFM movies were processed using a combination of Fijil/ImageJ (Schindelin et al. 2012) and in-house Python 3.8 functions. Alignment of images was performed using Trackmate (Tinevez et al. 2017) together with an in-house Python code, while PIV and FTTC calculations were performed using modified versions of $Q$. Tseng set of functions for FIJI/ImageJ (https://sites.google.com/site/qingzongtseng/ ; (Tseng et al. 2012)), with further plotting and calculations made using Python 3.8 homemade functions (https://github.com/phpuech/TFM). We used the Anaconda Python distribution (https://www.anaconda.com/), with the packages Seaborn, Matplotlib, Scipy, Numpy, Scikit as main dependencies. All data analysis was performed on Linux 64 bits machines.

Data plotting and significance testing were performed on Linux or Windows 64 bits machines using Python, R and/or Graphpad Prism (6 or 7). We used non parametric tests by default since our data was observed to be often largely distributed and not gaussian. If not stated otherwise, one data point corresponds to one measurement, that is, either one median value for a gel or a cell (AFM), or the one value calculated for a cell (spreading, TFM). 


\section{Acknowledgments}

The authors thank the INSERM Cell Culture Facility (PCC).

Part of this work was supported by institutional grants from INSERM, CNRS and Aix-Marseille University to the LAI and CINAM.

FM was supported by a PhD grant from the European Union's Horizon 2020 research and innovation programme under the Marie Skłodowska-Curie grant agreement 713750, with the financial support of the Regional Council of Provence- Alpes-Côte d'Azur and with of the A*MIDEX (ANR-11-IDEX-0001-02), funded by the Investissements d'Avenir project funded by the French Government, managed by the French National Research Agency (ANR)

RT was supported by a PhD grant from CENTURI (Turing Center for Living systems, Marseille, France), funded from the «Investissements d'Avenir » French Government program managed by the French National Research Agency (ANR-16-CONV-0001) and from Excellence Initiative of Aix-Marseille University - A*MIDEX.

We also thank CENTURI for the help we got from Q. Tseng for using his set of macros, under the form of a shared project in the frame of the engineer platform (https://centuri-livingsystems.org/multi-engineering-platform/). The authors want to personally thank him for his dedication and help over the very troubled pandemic times we are through. 


\section{Contributions}

FM did the experimental work, analyzed the data and wrote the article. MPB did all cell constructs and helped for cell maintenance and FACS analysis. RT implemented the refined alignment procedure used in the analysis. KS and PHP designed the study, performed some experiments, implemented novel analysis and wrote the article. All co-authors edited the manuscript.

The authors declare no competing interests. 


\section{References}

Bashour, Keenan T, Jones Tsai, Keyue Shen, Joung-Hyun Lee, Eileen Sun, Michael C Milone, Michael L Dustin, and Lance C Kam. 2014. 'Cross Talk between CD3 and CD28 Is Spatially Modulated by Protein Lateral Mobility.' Molecular and Cellular Biology 34 (6): 955-64. https://doi.org/10.1128/MCB.00842-13.

Brodovitch, Alexandre, Pierre Bongrand, and Anne Pierres. 2013. 'T Lymphocytes Sense Antigens within Seconds and Make a Decision within One Minute'. Journal of Immunology (Baltimore, Md.: 1950) 191 (5): 2064-71. https://doi.org/10.4049/jimmunol.1300523.

Bufi, Nathalie, Michael Saitakis, Stéphanie Dogniaux, Oscar Buschinger, Armelle Bohineust, Alain Richert, Mathieu Maurin, Claire Hivroz, and Atef Asnacios. 2015. 'Human Primary Immune Cells Exhibit Distinct Mechanical Properties That Are Modified by Inflammation'. Biophysical Journal 108 (9): $2181-90$. https://doi.org/10.1016/j.bpj.2015.03.047.

Butler, James P., Iva Marija Tolić-Nørrelykke, Ben Fabry, and Jeffrey J. Fredberg. 2002. 'Traction Fields, Moments, and Strain Energy That Cells Exert on Their Surroundings'. American Journal of Physiology-Cell Physiology $282 \quad$ (3): $\quad$ C595-605. https://doi.org/10.1152/ajpcell.00270.2001.

Butt, H.-J., and M. Jaschke. 1995. 'Calculation of Thermal Noise in Atomic Force Microscopy'. Nanotechnology 6 (1): 1. https://doi.org/10.1088/0957-4484/6/1/001.

Cazaux, Séverine, Anaïs Sadoun, Martine Biarnes-Pelicot, Manuel Martinez, Sameh Obeid, Pierre Bongrand, Laurent Limozin, and Pierre-Henri Puech. 2016. 'Synchronizing Atomic Force Microscopy Force Mode and Fluorescence Microscopy in Real Time for Immune Cell Stimulation and Activation Studies'. Ultramicroscopy 160 (January): 168-81. https://doi.org/10.1016/j.ultramic.2015.10.014.

Chen, Bi-Chang, Wesley R. Legant, Kai Wang, Lin Shao, Daniel E. Milkie, Michael W. Davidson, Chris Janetopoulos, et al. 2014. 'Lattice Light-Sheet Microscopy: Imaging Molecules to Embryos at High Spatiotemporal Resolution'. Science 346 (6208): 1257998. https://doi.org/10.1126/science.1257998.

Chen, Yunfeng, Lining Ju, Muaz Rushdi, Chenghao Ge, and Cheng Zhu. 2017. 'Receptor-Mediated Cell Mechanosensing'. Molecular Biology of the Cell 28 (23): 3134-55. https://doi.org/10.1091/mbc.E17-04-0228.

Comrie, William A., Alexander Babich, and Janis K. Burkhardt. 2015. 'F-Actin Flow Drives Affinity Maturation and Spatial Organization of LFA-1 at the Immunological Synapse'. The Journal of Cell Biology 208 (4): 475-91. https://doi.org/10.1083/jcb.201406121.

Dillard, Pierre, Rajat Varma, Kheya Sengupta, and Laurent Limozin. 2014. 'Ligand-Mediated Friction Determines Morphodynamics of Spreading T Cells'. Biophysical Journal 107 (11): 2629-38. https://doi.org/10.1016/j.bpj.2014.10.044.

Edelstein, Arthur, Nenad Amodaj, Karl Hoover, Ron Vale, and Nico Stuurman. 2010. 'Computer Control of Microscopes Using MManager'. Current Protocols in Molecular Biology / Edited by Frederick M. Ausubel ... [et Al.] Chapter 14 (October): Unit14.20. https://doi.org/10.1002/0471142727.mb1420s92.

Edelstein, Arthur D., Mark A. Tsuchida, Nenad Amodaj, Henry Pinkard, Ronald D. Vale, and Nico Stuurman. 2014. 'Advanced Methods of Microscope Control Using MManager Software'. Journal of Biological Methods 1 (2): e10. https://doi.org/10.14440/jbm.2014.36.

Elosegui-Artola, Alberto, Roger Oria, Yunfeng Chen, Anita Kosmalska, Carlos Pérez-González, Natalia Castro, Cheng Zhu, Xavier Trepat, and Pere Roca-Cusachs. 2016. 'Mechanical Regulation of a Molecular Clutch Defines Force Transmission and Transduction in Response to Matrix Rigidity'. Nature Cell Biology 18 (5): 540-48. https://doi.org/10.1038/ncb3336.

Engler, Adam J., Shamik Sen, H. Lee Sweeney, and Dennis E. Discher. 2006. 'Matrix Elasticity Directs Stem Cell Lineage Specification'. Cell 126 (4): 677-89. https://doi.org/10.1016/j.cell.2006.06.044. 
Flores, Luis R., Michael C. Keeling, Xiaoli Zhang, Kristina Sliogeryte, and Núria Gavara. 2019. 'Lifeact-TagGFP2 Alters F-Actin Organization, Cellular Morphology and Biophysical Behaviour'. Scientific Reports 9 (1). https://doi.org/10.1038/s41598-019-40092-w.

Geiger, B., and A. Bershadsky. 2001. 'Assembly and Mechanosensory Function of Focal Contacts.' Curr Opin Cell Biol 13 (5): 584-92.

Geiger, Benjamin, Joachim P. Spatz, and Alexander D. Bershadsky. 2009. 'Environmental Sensing through Focal Adhesions'. Nature Reviews Molecular Cell Biology 10 (1): 21-33. https://doi.org/10.1038/nrm2593.

Grakoui, A., S. K. Bromley, C. Sumen, M. M. Davis, A. S. Shaw, P. M. Allen, and M. L. Dustin. 1999. 'The Immunological Synapse: A Molecular Machine Controlling T Cell Activation.' Science 285 (5425): 221-27.

He, Hai-Tao, and Pierre Bongrand. 2012. 'Membrane Dynamics Shape TCR-Generated Signaling'. Frontiers in Immunology 3: 90. https://doi.org/10.3389/fimmu.2012.00090.

Henry, Steven J., Christopher S. Chen, John C. Crocker, and Daniel A. Hammer. 2015. 'Protrusive and Contractile Forces of Spreading Human Neutrophils'. Biophysical Journal 109 (4): 699-709. https://doi.org/10.1016/j.bpj.2015.05.041.

Herant, M. 2006. 'Mechanics of Neutrophil Phagocytosis: Experiments and Quantitative Models'. Journal of Cell Science 119 (9): 1903-13. https://doi.org/10.1242/jcs.02876.

Hivroz, Claire, and Michael Saitakis. 2016. 'Biophysical Aspects of T Lymphocyte Activation at the Immune Synapse'. Frontiers in Immunology 7 (February). https://doi.org/10.3389/fimmu.2016.00046.

Hornung, Alexander, Thomas Sbarrato, Nicolas Garcia-Seyda, Laurene Aoun, Xuan Luo, Martine Biarnes-Pelicot, Olivier Theodoly, and Marie-Pierre Valignat. 2020. 'A Bistable Mechanism Mediated by Integrins Controls Mechanotaxis of Leukocytes'. Biophysical Journal 118 (3): 565-77. https://doi.org/10.1016/j.bpj.2019.12.013.

$\mathrm{Hu}$, Kenneth H., and Manish J. Butte. 2016. 'T Cell Activation Requires Force Generation'. The Journal of Cell Biology 213 (5): 535-42. https://doi.org/10.1083/jcb.201511053.

Hui, King Lam, Lakshmi Balagopalan, Lawrence E. Samelson, and Arpita Upadhyaya. 2015. 'Cytoskeletal Forces during Signaling Activation in Jurkat T-Cells'. Molecular Biology of the Cell 26 (4): 685-95. https://doi.org/10.1091/mbc.E14-03-0830.

Huse, Morgan. 2017. 'Mechanical Forces in the Immune System'. Nature Reviews Immunology 17 (11): 679-90. https://doi.org/10.1038/nri.2017.74.

Husson, Julien, Karine Chemin, Armelle Bohineust, Claire Hivroz, and Nelly Henry. 2011. 'Force Generation upon T Cell Receptor Engagement'. Edited by Javed N. Agrewala. PLoS ONE 6 (5): e19680. https://doi.org/10.1371/journal.pone.0019680.

Jankowska, Katarzyna I., Edward K. Williamson, Nathan H. Roy, Daniel Blumenthal, Vidhi Chandra, Tobias Baumgart, and Janis K. Burkhardt. 2018. 'Integrins Modulate T Cell Receptor Signaling by Constraining Actin Flow at the Immunological Synapse'. Frontiers in Immunology 9 (January). https://doi.org/10.3389/fimmu.2018.00025.

Janmey, Paul A., Jessamine P. Winer, Maria E. Murray, and Qi Wen. 2009. 'The Hard Life of Soft Cells'. Cell Motility and the Cytoskeleton 66 (8): 597-605. https://doi.org/10.1002/cm.20382.

Jannat, Risat A., Micah Dembo, and Daniel A. Hammer. 2011. 'Traction Forces of Neutrophils Migrating on Compliant Substrates'. Biophysical Journal 101 (3): 575-84. https://doi.org/10.1016/j.bpj.2011.05.040.

Jaumouillé, Valentin, and Clare M. Waterman. 2020. 'Physical Constraints and Forces Involved in Phagocytosis'. Frontiers in Immunology 11. https://doi.org/10.3389/fimmu.2020.01097.

Jin, Weiyang, Fella Tamzalit, Parthiv Kant Chaudhuri, Charles T. Black, Morgan Huse, and Lance C. Kam. 2019. 'T Cell Activation and Immune Synapse Organization Respond to the Microscale Mechanics of Structured Surfaces'. Proceedings of the National Academy of Sciences 116 (40): 19835-40. https://doi.org/10.1073/pnas.1906986116.

$\mathrm{Ju}$, Lining, Yunfeng Chen, Kaitao Li, Zhou Yuan, Baoyu Liu, Shaun P. Jackson, and Cheng Zhu. 2017. 'Dual Biomembrane Force Probe Enables Single-Cell Mechanical Analysis of Signal Crosstalk between Multiple Molecular Species'. Scientific Reports 7 (1). 
https://doi.org/10.1038/s41598-017-13793-3.

Judokusumo, Edward, Erdem Tabdanov, Sudha Kumari, Michael L. Dustin, and Lance C. Kam. 2012. 'Mechanosensing in T Lymphocyte Activation'. Biophysical Journal 102 (2): L5-7. https://doi.org/10.1016/j.bpj.2011.12.011.

Jung, Philipp, Xiangda Zhou, Sandra Iden, Markus Bischoff, and Bin Qu. 2021. 'T Cell Stiffness Is Enhanced upon Formation of Immunological Synapse'. ELife 10 (July): e66643. https://doi.org/10.7554/eLife.66643.

Kim, Hye-Ran, YeVin Mun, Kyung-Sik Lee, Yoo-Jin Park, Jeong-Su Park, Jin-Hwa Park, Bu-Nam Jeon, et al. 2018. 'T Cell Microvilli Constitute Immunological Synaptosomes That Carry Messages to Antigen-Presenting Cells'. Nature Communications 9 (1). https://doi.org/10.1038/s41467-018-06090-8.

Kim, Sarah Hyun Ji, and Daniel A. Hammer. 2021. 'Integrin Cross-Talk Modulates Stiffness-Independent Motility of CD4+ T Lymphocytes'. Molecular Biology of the Cell 32 (18): 1749-57. https://doi.org/10.1091/mbc.E21-03-0131.

Kim, Sun Taek, Yongdae Shin, Kristine Brazin, Robert J. Mallis, Zhen-Yu J. Sun, Gerhard Wagner, Matthew J. Lang, and Ellis L. Reinherz. 2012. 'TCR Mechanobiology: Torques and Tunable Structures Linked to Early T Cell Signaling. Frontiers in Immunology 3: 76. https://doi.org/10.3389/fimmu.2012.00076.

Kim, Sun Taek, Koh Takeuchi, Zhen-Yu J Sun, Maki Touma, Carlos E Castro, Amr Fahmy, Matthew J Lang, Gerhard Wagner, and Ellis L Reinherz. 2009. 'The Alphabeta T Cell Receptor Is an Anisotropic Mechanosensor'. J Biol Chem 284 (45): 31028-37. https://doi.org/10.1074/jbc.M109.052712.

Klotzsch, Enrico, and Gerhard J Schütz. 2013. 'Improved Ligand Discrimination by Force-Induced Unbinding of the T Cell Receptor from Peptide-MHC.' Biophysical Journal 104 (8): 1670-75. https://doi.org/10.1016/j.bpj.2013.03.023.

Kumari, Anita, Judith Pineau, Ana-Maria Lennon-Duménil, Martial Balland, and Paolo Pierobon. 2020. 'Traction Force Microscopy to Study B Lymphocyte Activation'. JoVE (Journal of Visualized Experiments), no. 161 (July): e60947. https://doi.org/10.3791/60947.

Kumari, Anita, Judith Pineau, Pablo J. Sáez, Mathieu Maurin, Danielle Lankar, Mabel San Roman, Katharina Hennig, et al. 2019. 'Actomyosin-Driven Force Patterning Controls Endocytosis at the Immune Synapse'. Nature Communications 10 (1): 2870. https://doi.org/10.1038/s41467-019-10751-7.

Lekka, Małgorzata, Kajangi Gnanachandran, Andrzej Kubiak, Tomasz Zieliński, and Joanna Zemła. 2021. 'Traction Force Microscopy - Measuring the Forces Exerted by Cells'. Micron 150 (November): 103138. https://doi.org/10.1016/j.micron.2021.103138.

Limozin, Laurent, Marcus Bridge, Pierre Bongrand, Omer Dushek, Philip Anton van der Merwe, and Philippe Robert. 2019. 'TCR-PMHC Kinetics under Force in a Cell-Free System Show No Intrinsic Catch Bond, but a Minimal Encounter Duration before Binding'. Proceedings of the National Academy of Sciences of the United States of America 116 (34): 16943-48. https://doi.org/10.1073/pnas.1902141116.

Limozin, Laurent, and Pierre-Henri Puech. 2019. 'Membrane Organization and Physical Regulation of Lymphocyte Antigen Receptors: A Biophysicist's Perspective'. The Journal of Membrane Biology 252 (4-5): https://doi.org/10.1007/s00232-019-00085-2.

Liu, Baoyu, Wei Chen, Brian D. Evavold, and Cheng Zhu. 2014. 'Accumulation of Dynamic Catch Bonds between TCR and Agonist Peptide-MHC Triggers T Cell Signaling'. Cell 157 (2): 357-68. https://doi.org/10.1016/j.cell.2014.02.053.

Liu, Baoyu, Elizabeth M. Kolawole, and Brian D. Evavold. 2021. 'Mechanobiology of T Cell Activation: To Catch a Bond'. Annual Review of Cell and Developmental Biology 37 (1): 65-87. https://doi.org/10.1146/annurev-cellbio-120219-055100.

Liu, Yang, Lori Blanchfield, Victor Pui-Yan Ma, Rakieb Andargachew, Kornelia Galior, Zheng Liu, Brian Evavold, and Khalid Salaita. 2016. 'DNA-Based Nanoparticle Tension Sensors Reveal That T-Cell Receptors Transmit Defined PN Forces to Their Antigens for Enhanced Fidelity'. Proceedings of the National Academy of Sciences 113 (20): 5610-15. 
https://doi.org/10.1073/pnas.1600163113.

Malissen, Bernard, and Pierre Bongrand. 2015. 'Early T Cell Activation: Integrating Biochemical, Structural, and Biophysical Cues'. Annual Review of Immunology 33 (1): 539-61. https://doi.org/10.1146/annurev-immunol-032414-112158.

Martiel, Jean-Louis, Aldo Leal, Laetitia Kurzawa, Martial Balland, Irene Wang, Timothée Vignaud, Qingzong Tseng, and Manuel Théry. 2015. 'Measurement of Cell Traction Forces with ImageJ'. In Methods in Cell Biology, 125:269-87. Elsevier. https://doi.org/10.1016/bs.mcb.2014.10.008.

Martino, Fabiana, Ana R. Perestrelo, Vladimír Vinarský, Stefania Pagliari, and Giancarlo Forte. 2018. 'Cellular Mechanotransduction: From Tension to Function'. Frontiers in Physiology 9. https://www.frontiersin.org/article/10.3389/fphys.2018.00824.

Monks, Colin R. F., Benjamin A. Freiberg, Hannah Kupfer, Noah Sciaky, and Abraham Kupfer. 1998. 'Three-Dimensional Segregation of Supramolecular Activation Clusters in T Cells'. Nature 395 (6697): 82-86. https://doi.org/10.1038/25764.

Mustapha, Farah, Kheya Sengupta, and Pierre-Henri Puech. 2022. 'Protocol for Measuring Weak Cellular Traction Forces Using Well-Controlled Ultra-Soft Polyacrylamide Gels'. STAR Protocols 3 (1): 101133. https://doi.org/10.1016/j.xpro.2022.101133.

O'Connor, Roddy S, Xueli Hao, Keyue Shen, Keenan Bashour, Tatiana Akimova, Wayne W Hancock, Lance C Kam, and Michael C Milone. 2012. 'Substrate Rigidity Regulates Human T Cell Activation and Proliferation.' Journal of Immunology (Baltimore, Md. : 1950) 189 (3): 1330-39. https://doi.org/10.4049/jimmunol.1102757.

Pelham, Robert J., and Yu-li Wang. 1997. 'Cell Locomotion and Focal Adhesions Are Regulated by Substrate Flexibility'. Proceedings of the National Academy of Sciences 94 (25): 13661-65. https://doi.org/10.1073/pnas.94.25.13661.

Pierres, Anne, Anne-Marie Benoliel, Dominique Touchard, and Pierre Bongrand. 2008. 'How Cells Tiptoe on Adhesive Surfaces before Sticking.' Biophysical Journal 94 (10): 4114-22. https://doi.org/10.1529/biophysj.107.125278.

Puech, Pierre-Henri, and Pierre Bongrand. 2021. 'Mechanotransduction as a Major Driver of Cell Behaviour: Mechanisms, and Relevance to Cell Organization and Future Research'. Open Biology 11 (11): 210256. https://doi.org/10.1098/rsob.210256.

Puech, Pierre-Henri, Damien Nevoltris, Philippe Robert, Laurent Limozin, Claude Boyer, and Pierre Bongrand. 2011. 'Force Measurements of TCR/PMHC Recognition at T Cell Surface'. Edited by Daniel J. Muller. PLoS ONE 6 (7): e22344. https://doi.org/10.1371/journal.pone.0022344.

Reichardt, Peter, Bastian Dornbach, and Matthias Gunzer. 2010. 'APC, T Cells, and the Immune Synapse'. Current Topics in Microbiology and Immunology 340: 229-49. https://doi.org/10.1007/978-3-642-03858-7_12.

Rheinlaender, Johannes, Andrea Dimitracopoulos, Bernhard Wallmeyer, Nils M. Kronenberg, Kevin J. Chalut, Malte C. Gather, Timo Betz, Guillaume Charras, and Kristian Franze. 2020. 'Cortical Cell Stiffness Is Independent of Substrate Mechanics'. Nature Materials 19 (9): 1019-25. https://doi.org/10.1038/s41563-020-0684-x.

Sadoun, Anaïs, Martine Biarnes-Pelicot, Laura Ghesquiere-Dierickx, Ambroise Wu, Olivier Théodoly, Laurent Limozin, Yannick Hamon, and Pierre-Henri Puech. 2021. 'Controlling T Cells Spreading, Mechanics and Activation by Micropatterning'. Scientific Reports 11 (1): 6783. https://doi.org/10.1038/s41598-021-86133-1.

Sage, Peter T., Laya M. Varghese, Roberta Martinelli, Tracey E. Sciuto, Masataka Kamei, Ann M. Dvorak, Timothy A. Springer, Arlene H. Sharpe, and Christopher V. Carman. 2012. 'Antigen Recognition Is Facilitated by Invadosome-like Protrusions Formed by Memory/Effector T Cells'. The Journal of Immunology 188 (8): 3686-99. https://doi.org/10.4049/jimmunol.1102594.

Saitakis, Michael, Stéphanie Dogniaux, Christel Goudot, Nathalie Bufi, Sophie Asnacios, Mathieu Maurin, Clotilde Randriamampita, Atef Asnacios, and Claire Hivroz. 2017. 'Different TCR-Induced T Lymphocyte Responses Are Potentiated by Stiffness with Variable Sensitivity'. ELife 6 (June). https://doi.org/10.7554/eLife.23190. 
Sawicka, Anna, Avin Babataheri, Stéphanie Dogniaux, Abdul I. Barakat, David Gonzalez-Rodriguez, Claire Hivroz, and Julien Husson. 2017. 'Micropipette Force Probe to Quantify Single-Cell Force Generation: Application to T-Cell Activation'. Molecular Biology of the Cell 28 (23): 3229-39. https://doi.org/10.1091/mbc.E17-06-0385.

Schindelin, Johannes, Ignacio Arganda-Carreras, Erwin Frise, Verena Kaynig, Mark Longair, Tobias Pietzsch, Stephan Preibisch, et al. 2012. 'Fiji: An Open-Source Platform for Biological-Image Analysis'. Nature Methods 9 (7): 676-82. https://doi.org/10.1038/nmeth.2019.

Schwarz, Ulrich S., and Samuel A. Safran. 2013. 'Physics of Adherent Cells'. Reviews of Modern Physics 85 (3): 1327-81. https://doi.org/10.1103/RevModPhys.85.1327.

Sliogeryte, Kristina, Stephen D. Thorpe, Zhao Wang, Clare L. Thompson, Nuria Gavara, and Martin M. Knight. 2016. 'Differential Effects of LifeAct-GFP and Actin-GFP on Cell Mechanics Assessed Using Micropipette Aspiration'. Journal of Biomechanics 49 (2): 310-17. https://doi.org/10.1016/j.jbiomech.2015.12.034.

Solon, Jérôme, Ilya Levental, Kheya Sengupta, Penelope C. Georges, and Paul A. Janmey. 2007. 'Fibroblast Adaptation and Stiffness Matching to Soft Elastic Substrates'. Biophysical Journal 93 (12): 4453-61. https://doi.org/10.1529/biophysj.106.101386.

Spillane, Katelyn M., and Pavel Tolar. 2018. 'Mechanics of Antigen Extraction in the B Cell Synapse'. Molecular Immunology 101 (September): 319-28. https://doi.org/10.1016/j.molimm.2018.07.018.

Style, Robert W., Rostislav Boltyanskiy, Guy K. German, Callen Hyland, Christopher W. MacMinn, Aaron F. Mertz, Larry A. Wilen, Ye Xu, and Eric R. Dufresne. 2014. 'Traction Force Microscopy in Physics and Biology'. Soft Matter 10 (23): 4047-55. https://doi.org/10.1039/C4SM00264D.

Thauland, Timothy J., Kenneth H. Hu, Marc A. Bruce, and Manish J. Butte. 2017. 'Cytoskeletal Adaptivity Regulates T Cell Receptor Signaling'. Science Signaling 10 (469): eaah3737. https://doi.org/10.1126/scisignal.aah3737.

Tinevez, Jean-Yves, Nick Perry, Johannes Schindelin, Genevieve M. Hoopes, Gregory D. Reynolds, Emmanuel Laplantine, Sebastian Y. Bednarek, Spencer L. Shorte, and Kevin W. Eliceiri. 2017. 'TrackMate: An Open and Extensible Platform for Single-Particle Tracking'. Methods (San Diego, Calif.) 115 (February): $80-90$. https://doi.org/10.1016/j.ymeth.2016.09.016.

Tse, Justin R., and Adam J. Engler. 2010. 'Preparation of Hydrogel Substrates with Tunable Mechanical Properties'. Current Protocols in Cell Biology 47 (1): 10.16.1-10.16.16. https://doi.org/10.1002/0471143030.cb1016s47.

Tseng, Qingzong, Eve Duchemin-Pelletier, Alexandre Deshiere, Martial Balland, Hervé Guillou, Odile Filhol, and Manuel Théry. 2012. 'Spatial Organization of the Extracellular Matrix Regulates Cell-Cell Junction Positioning.' Proceedings of the National Academy of Sciences of the United States of America 109 (5): 1506-11. https://doi.org/10.1073/pnas.1106377109.

Vogel, Viola, and Michael Sheetz. 2006. 'Local Force and Geometry Sensing Regulate Cell Functions'. Nature Reviews Molecular Cell Biology 7 (4): 265-75. https://doi.org/10.1038/nrm1890.

Vorselen, Daan, Sarah R Barger, Yifan Wang, Wei Cai, Julie A Theriot, Nils C Gauthier, and Mira Krendel. 2021. 'Phagocytic "Teeth" and Myosin-II "Jaw" Power Target Constriction during Phagocytosis'. Edited by Pekka Lappalainen, Suzanne R Pfeffer, Pekka Lappalainen, and Renaud Poincloux. ELife 10 (October): e68627. https://doi.org/10.7554/eLife.68627.

Vorselen, Daan, Yifan Wang, Miguel M. de Jesus, Pavak K. Shah, Matthew J. Footer, Morgan Huse, Wei Cai, and Julie A. Theriot. 2020. 'Microparticle Traction Force Microscopy Reveals Subcellular Force Exertion Patterns in Immune Cell-Target Interactions'. Nature Communications 11 (1). https://doi.org/10.1038/s41467-019-13804-z.

Wahl, Astrid, Céline Dinet, Pierre Dillard, Aya Nassereddine, Pierre-Henri Puech, Laurent Limozin, and Kheya Sengupta. 2019. 'Biphasic Mechanosensitivity of $\mathrm{T}$ Cell Receptor-Mediated Spreading of Lymphocytes'. Proceedings of the National Academy of 
bioRxiv preprint doi: https://doi.org/10.1101/2022.02.11.480084; this version posted February 11, 2022. The copyright holder for this

preprint (which was not certified by peer review) is the author/funder, who has granted bioRxiv a license to display the preprint in perpetuity. It is made available under aCC-BY-NC-ND 4.0 International license.

Sciences 116 (13): 5908-13. https://doi.org/10.1073/pnas.1811516116.

Zak, Alexandra, Sara Violeta Merino-Cortés, Anaïs Sadoun, Farah Mustapha, Avin Babataheri, Stéphanie Dogniaux, Sophie Dupré-Crochet, et al. 2021. 'Rapid Viscoelastic Changes Are a Hallmark of Early Leukocyte Activation'. Biophysical Journal 120 (9): 1692-1704. https://doi.org/10.1016/j.bpj.2021.02.042. 


\section{Figures captions}

Fig. 1: Gel characterization using atomic force microscopy. A: Schematics of gel indentation using a bead modified AFM cantilever. B: Transmission micrograph showing the cantilever on the gel. C: Representative force vs. indentation curve (light red) with a Hertz-like adjustment (green). The retract curve (dark red) shows very little adhesive hysteresis. D: Representative map of the Young modulus, each pixel being of a size comparable to a T cell. E: Measured Young modulus vs. expected modulus from the gel composition (see Material and Methods) with the region of interest corresponding to APCs (Bufi et al. 2015) indicated together with the traditional range used in TFM; insert represents the dispersion between three gels obtained three different days. F: Schematic of the antibody decorated gels, doped with fluorescent nanobeads. Two layers are seen close to the two interfaces. G: Fluorescence image at the focus on the upper nanobeads layer (bar $=50 \mu \mathrm{m})$. $\mathrm{H}$ : Image taken from the upper substrate interface when coated with a fluorescent antibody (bar $=50 \mu \mathrm{m})$. I: Effect of the presence of the nanobeads on the apparent Young modulus of the softest gels. J: Intensity profiles of the image in $\mathrm{H}$, color coded as the lines in $\mathrm{H}$, showing the homogeneity of the fluorescence intensity in the image.

Fig. 2: T cell spreading on gels and mechanical properties A: Schematics of the spreading experiments on antiCD3 coated gels of variable rigidity, the colored zone indicates the zone on which the focus is made to measure the cell's apparent area. B: Micrographs of a Lyf-GFP cell showing the presence of cellular extensions. C: Quantification of the apparent area of cells on the different substrates. Please note that this area is not the contact area per se. Typically $\sim 200$ cells were used in total per case. D: Schematics of the AFM indentation experiments on cells adhered on similar substrates as for spreading experiments. E: Micrograph showing the bead (white round spot) glued on the cantilever (dark gray triangle) in close proximity to a cell. F: Young modulus measurements as a function of substrate rigidity. The Young modulus has not been measured faithfully on cells adhered on the softest substrate (see text) and led us to report a NA here. Typically $\sim 20$ cells were used per condition.

Fig. 3 : Traction Force Microscopy. A: TFM experiment schematics, with the reference image taken before cell landing. B: Merged image of nanobeads (before displacement in cyan, after in blue) and of the cell sitting on the gel. C: Normalized map of PIV obtained from the nanobeads displacement. D: Stress norm map as calculated by FTTC with a regularization factor of 9e-10. E: Typical curve of sum of stresses (bottom) and total stored energy (top) on the entire map vs. time during the early recognition of the substrate by the cell. Typically, the two curves have the same overall morphologies. 
Fig. 4: Traction Force Microscopy of Lyf-GFP cells on different substrates. A: Three types of energy vs. time curves are typically observed, of very different morphologies (here with their baseline offset to zero after calculation before a 20 sec cut-off, red dashed line). B: Quantification of the SD of the fluctuating curves obtained for different coatings, at the very beginning of the experiments, where the cells are not exerting forces, and later, when they may do. This shows that fluctuating curves observed for bare or IgG2a coated substrates and aCD3 based ones are different, the latter exhibiting larger fluctuations of energy more likely due to cell interactions. C: Relative occurrence of the types of curves obtained in the different situations with antibody decorated substrates. D: Pooled maximum of the sum of stresses as a function of substrate coating. E: Pooled integrated energy over the time of the experiment (15 min). F: Integrated energy as a function of curve type and substrate (same data as in E). G: Relative occurrence of energy curve morphology for the same cell preparations seeded on gels of two gels of different rigidities, coated with aCD3. Note the small variability of the relative proportions of events introduced by cell culture aleas, compared with C. H: Pooled max stress sum and I: Pooled integrated energy for cells sitting on these gels. J: Same data as in I, separated by energy curve morphology and gel elasticity.

Fig. 5: Effect of transfection on the levels of stresses exerted by the cells on aCD3 coated gels. A: Quantification of the types of morphologies of energy curves. B: Pooled maximum of the sum of stresses and C: Pooled integrated energy as a function of the cell type. D: same data as in C, separated by energy curve morphology and cell type. Note that due to the coupling of experiments per cell culture lots, the data presented here for Lifeact-GFP cells is the same as in Fig. 4G to J . 
bioRxiv preprint doi: https://doi.org/10.1101/2022.02.11.480084; this version posted February 11, 2022. The copyright holder for this preprint (which was not certified by peer review) is the author/funder, who has granted bioRxiv a license to display the preprint in perpetuity. It is made available under aCC-BY-NC-ND 4.0 International license.

\section{Graphical abstract}

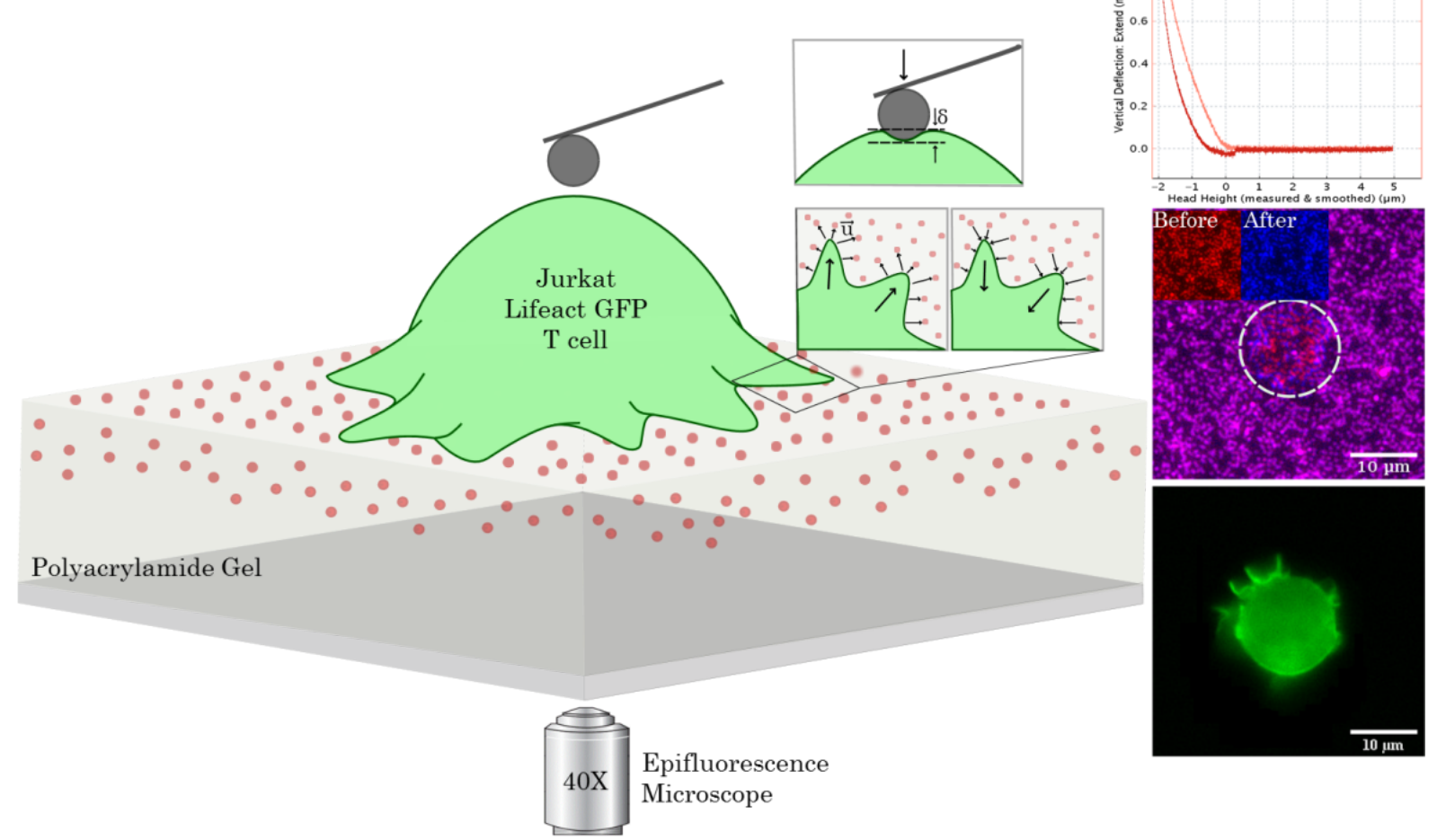


bioRxiv preprint doi: https://doi.org/10.1101/2022.02.11.480084; this version posted February 11, 2022. The copyright holder for this

preprint (which was not certified by peer review) is the author/funder, who has granted bioRxiv a license to display the preprint in perpetuity. It is made available under aCC-BY-NC-ND 4.0 International license.

\section{Figure 1}
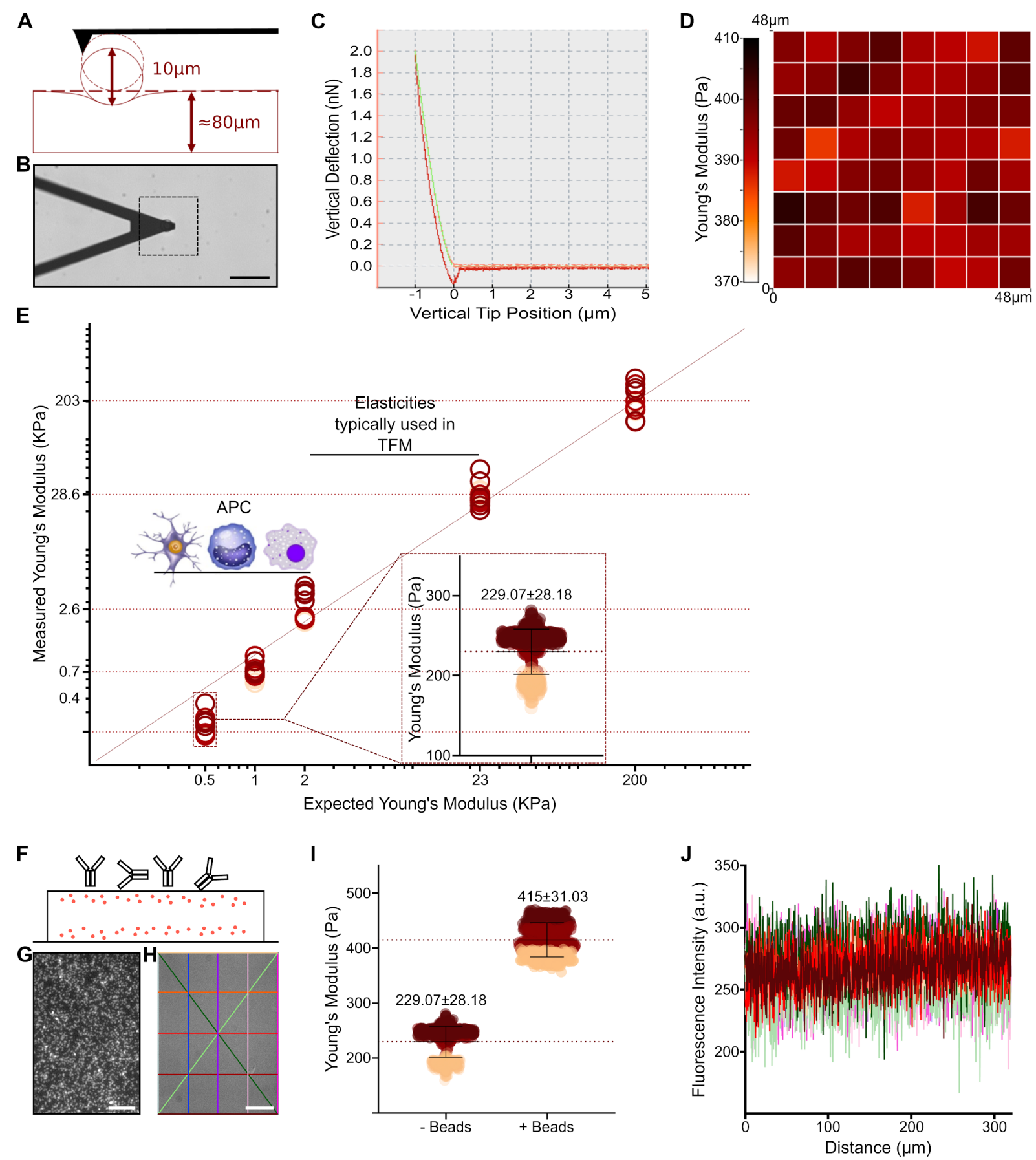
bioRxiv preprint doi: https://doi.org/10.1101/2022.02.11.480084; this version posted February 11, 2022. The copyright holder for this

preprint (which was not certified by peer review) is the author/funder, who has granted bioRxiv a license to display the preprint in perpetuity. It is made available under aCC-BY-NC-ND 4.0 International license.

\section{Figure 2}

A
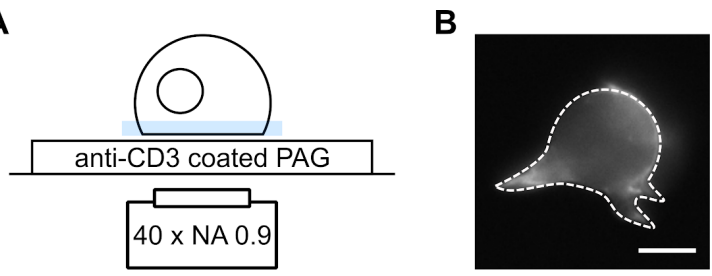

C
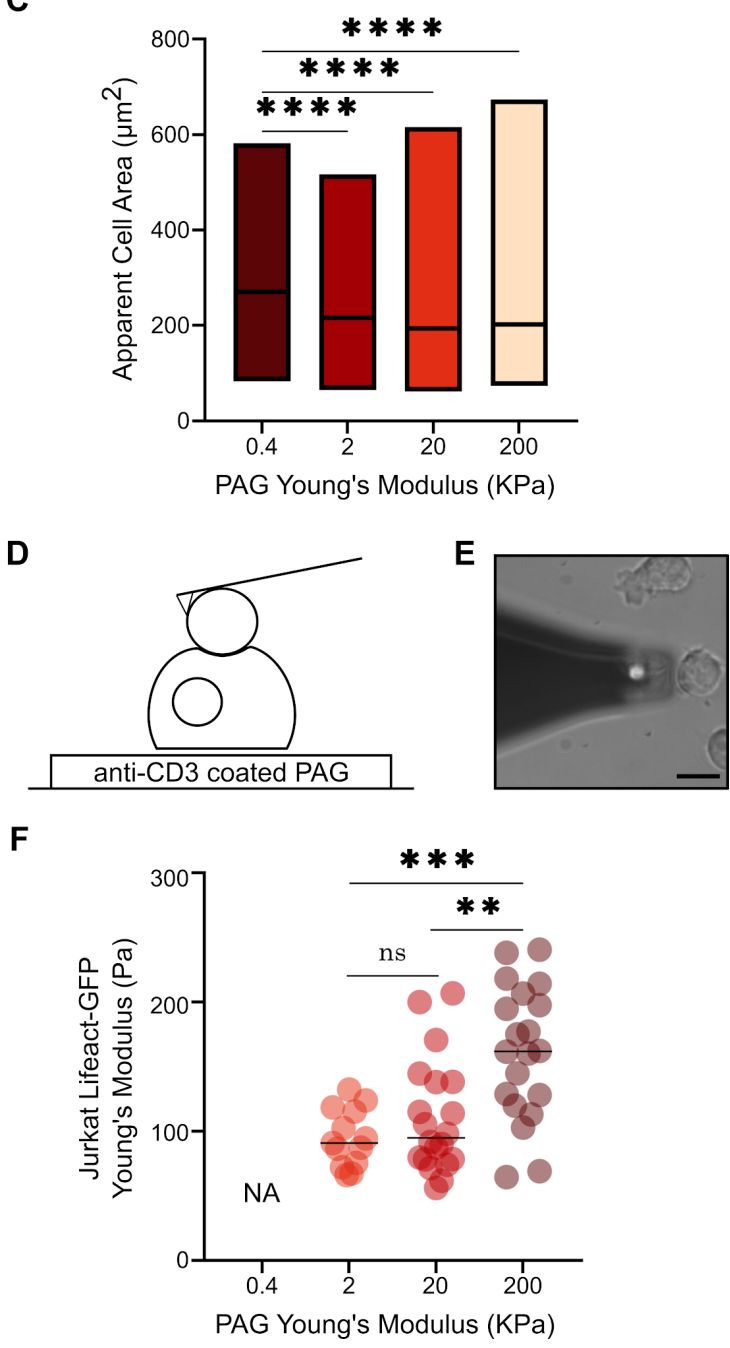
bioRxiv preprint doi: https://doi.org/10.1101/2022.02.11.480084; this version posted February 11, 2022. The copyright holder for this preprint (which was not certified by peer review) is the author/funder, who has granted bioRxiv a license to display the preprint in perpetuity. It is made available under aCC-BY-NC-ND 4.0 International license.

\section{Figure 3}

A
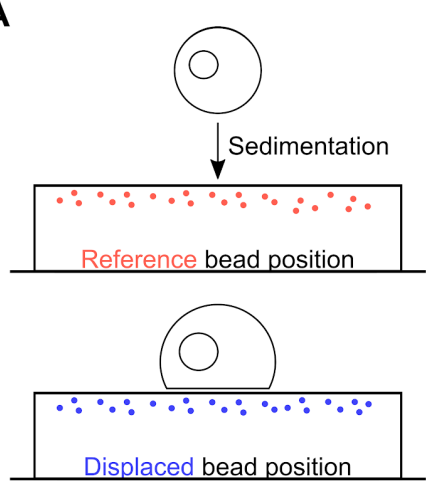

B

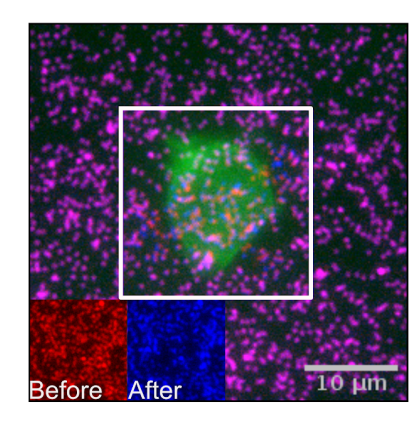

D

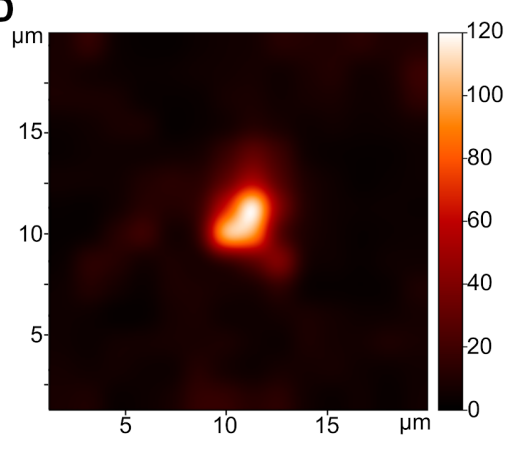

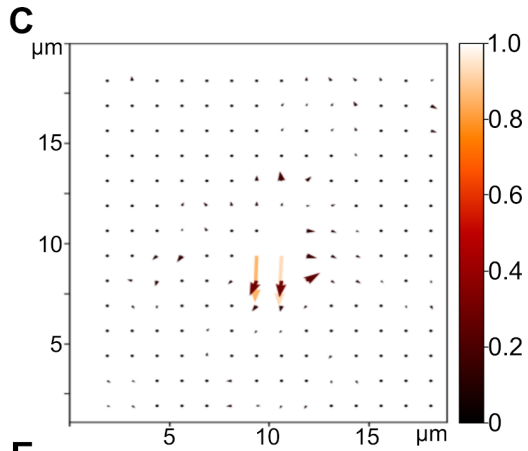

E

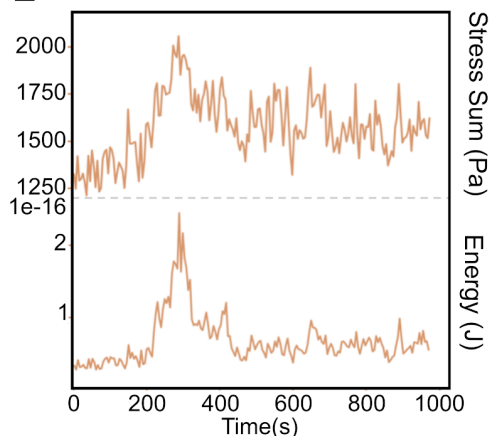


bioRxiv preprint doi: https://doi.org/10.1101/2022.02.11.480084; this version posted February 11, 2022. The copyright holder for this

preprint (which was not certified by peer review) is the author/funder, who has granted bioRxiv a license to display the preprint in perpetuity. It is made available under aCC-BY-NC-ND 4.0 International license.

\section{Figure 4}

A

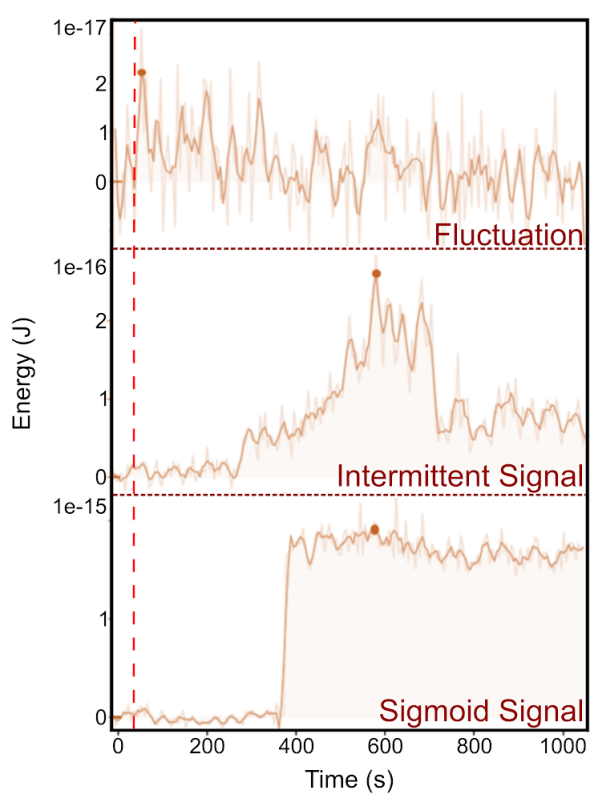

B

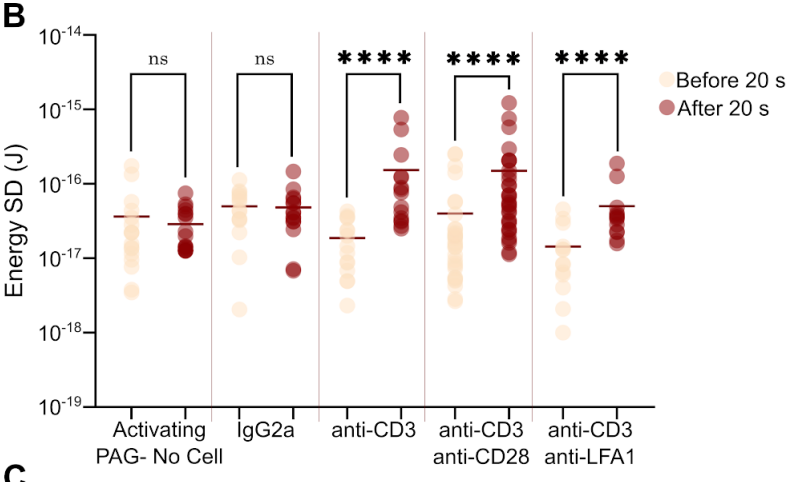

C
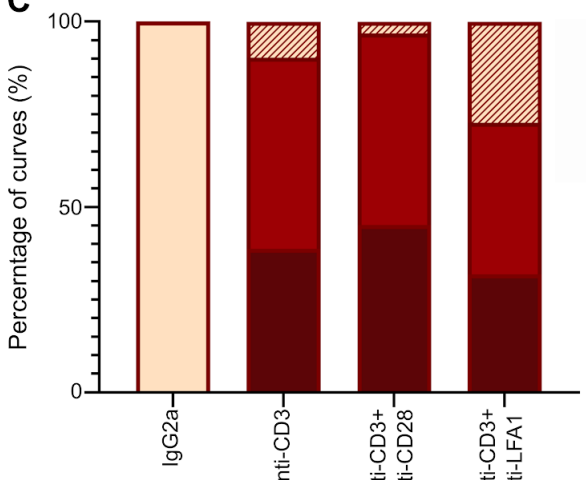

- Sigmoid Signal

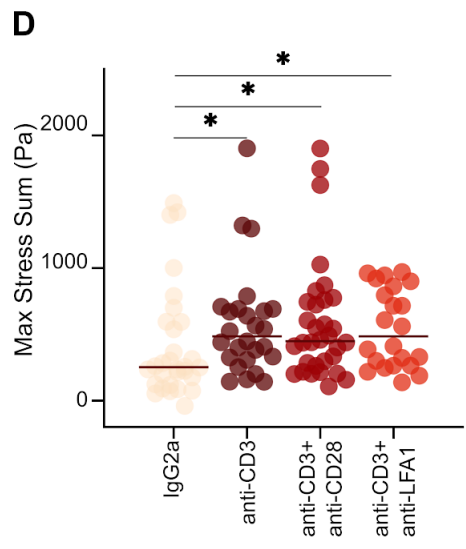

G

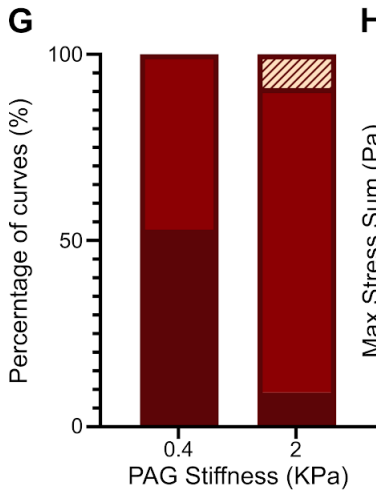

E

H

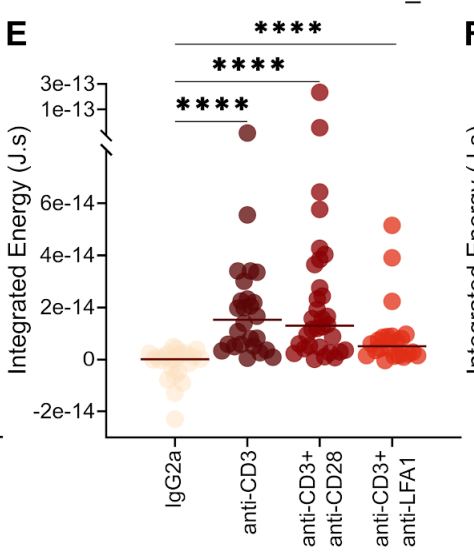

I

口Passive Fluctuation

Active Fluctuation

-Intermittent Signal

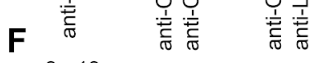
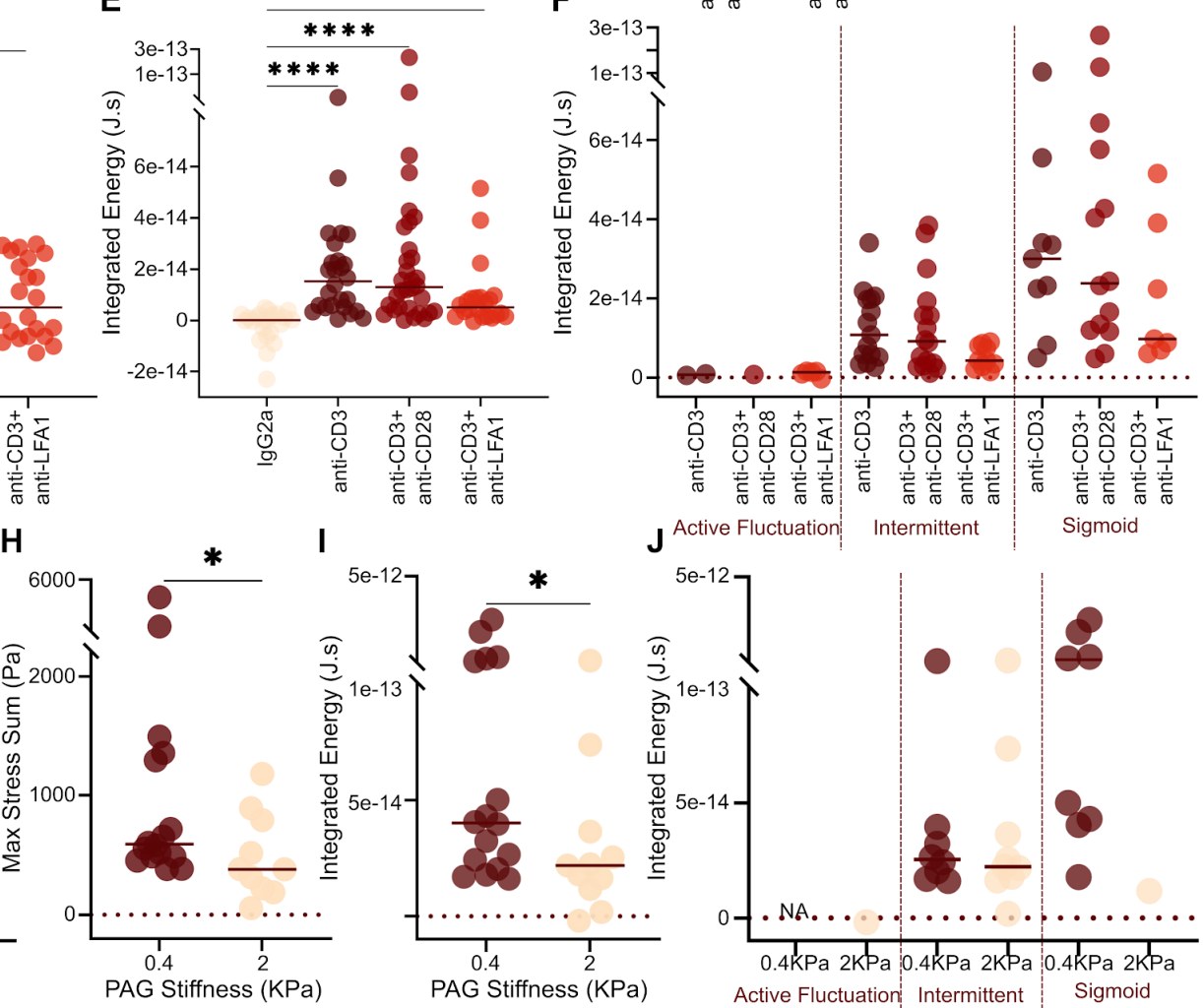


\section{Figure 5}
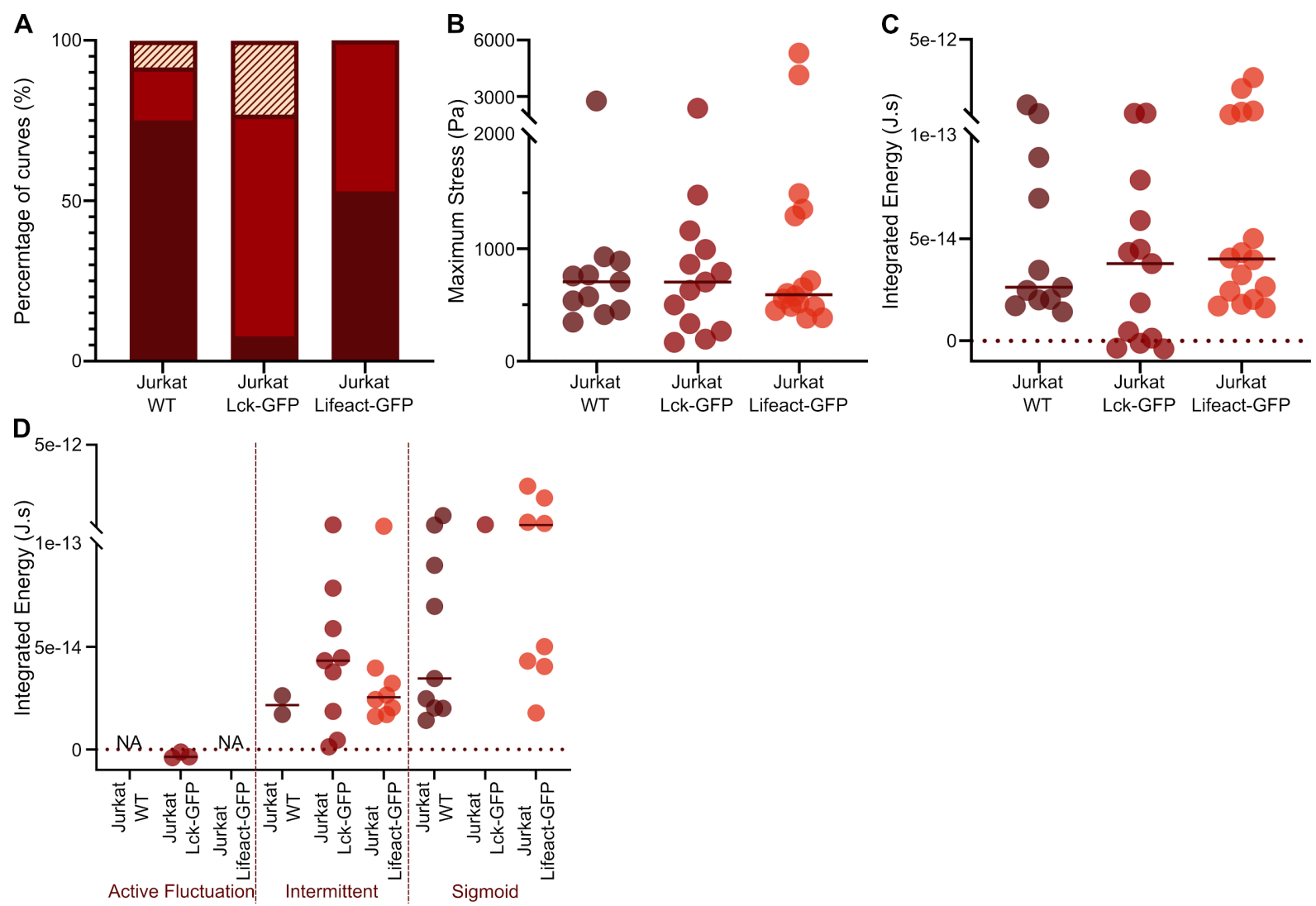


\section{Supplementary figures captions}

FigS1: Cytometry. Spectra for Jurkat WT, Lck-GFP (membrane labeling) and LifeAct-GFP (actin labeling) transfected Jurkat after cell sorting for high levels of expression post transfection..

FigS2: Gels mechanics and coating. A: Young moduli of the softest gels as a function of the indentation speed in the range accessible by classical AFM indentation on our set-up, with the same typical contact force $(2 \mathrm{nN})$. No large variation is observed, pointing toward a rather elastic behavior. B: Calibration curve (see text and (Hornung et al. 2020) that allows us to determine the average density of grafted antibodies from the intensities as measured in I. The red point corresponds to the average fluorescence intensity of the surface of the gel $(>3$ samples), which allows us to estimate the coating density reported in the main text.

FigS3 : Optimisation of the regularization parameter for FTTC. A: Type of data (Force vs. time) that was used to optimize the parameter, with the regions where baseline (noise) and signal were analyzed. B: Variation of the signal, noise and signal/noise as a function of the regularization factor. An evident change in intensity for both signals (decrease of the noise faster than the signal ; increasing $\mathrm{S} / \mathrm{N}$ ) was observed around $10^{\wedge}-9$. C: Beads images (overlay) and calculated PIV for a given time frame of a movie used for A, in the 'signal' zone. D: Reconstructed normalized force vector fields using FTTC and different regularization factors showing zones of interests. Left to right, as the regularization factor increases : decrease of the noise levels out of the higher signal zone, decrease of badly oriented force vectors, disappearance of bad vectors, loss of all signals. E: Energy values calculated vs. time for different regularization factors, showing the same patterns, but absolute levels decreasing as the regularization factor is increased. As a consequence, we choose to use the higher factor before the transitions observed in A, namely 9x10^-9 (Mustapha, Sengupta, and Puech 2022), which is consistent with values reported in the literature for similar cellular systems (B cells, (Kumari et al. 2020)) and by the published works of the developer of the FTTC Fiji plugin we used (Martiel et al. 2015; Tseng et al. 2012).

Fig. S4 : From spreading to contracting. A: Normalized PIVs and B: Corresponding normalized stress maps for different times points, one for each colored zone in C (number of pixels having a displacement norm larger than the noise in the initial image, vs. time) and D (corresponding calculated energy vs time). The cell spreads first (outward arrows in the second columns of vector maps) then pulls on the gel (inward arrows on the third column). The number of apparent pixels on which noticeable stresses are occuring increase (light yellow, orange, red) then decreases (red, light yellow) as the cell detaches, the energy coming back to its initial level, 
bioRxiv preprint doi: https://doi.org/10.1101/2022.02.11.480084; this version posted February 11,2022 . The copyright holder for this preprint (which was not certified by peer review) is the author/funder, who has granted bioRxiv a license to display the preprint in perpetuity. It is made available under aCC-BY-NC-ND 4.0 International license.

and even less (the noise here almost canceled in the end, and the cell had move away from the zone, the system then behaving as a cell free system, see Fig. 4). 
bioRxiv preprint doi: https://doi.org/10.1101/2022.02.11.480084; this version posted February $11,2022$. The copyright holder for this

preprint (which was not certified by peer review) is the author/funder, who has granted bioRxiv a license to display the preprint in perpetuity. It is made available under aCC-BY-NC-ND 4.0 International license.

Fig. S1

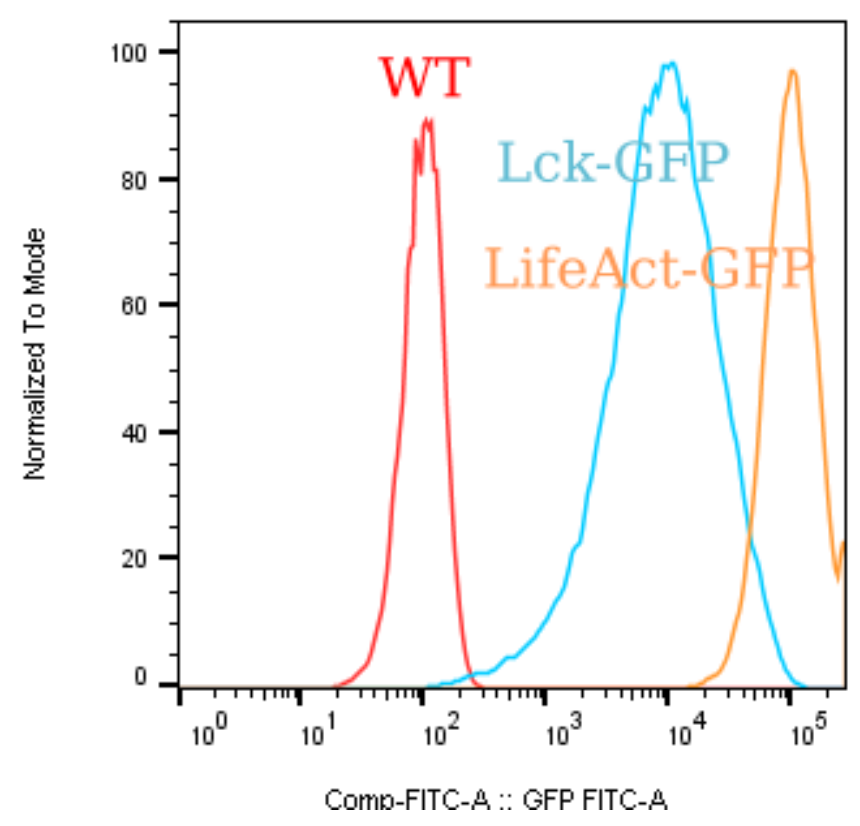


bioRxiv preprint doi: https://doi.org/10.1101/2022.02.11.480084; this version posted February 11, 2022. The copyright holder for this preprint (which was not certified by peer review) is the author/funder, who has granted bioRxiv a license to display the preprint in perpetuity. It is made available under aCC-BY-NC-ND 4.0 International license.

Fig. S2

A

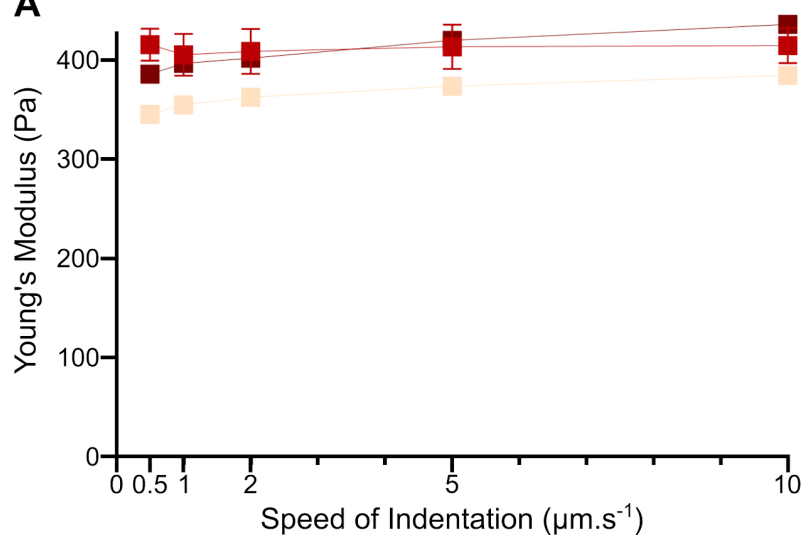

B

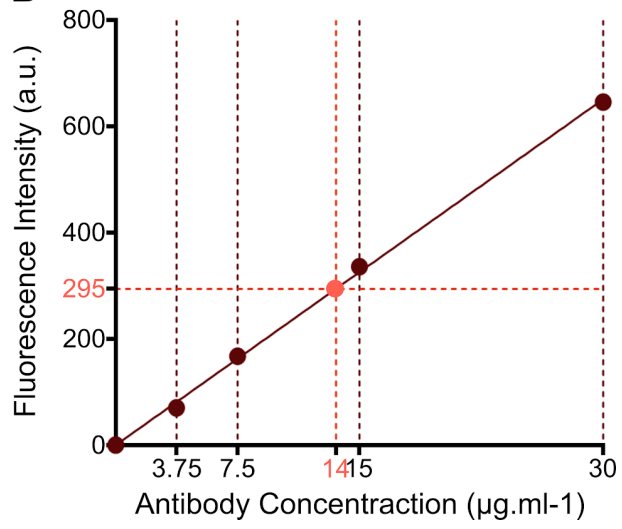


bioRxiv preprint doi: https://doi.org/10.1101/2022.02.11.480084; this version posted February 11, 2022. The copyright holder for this

preprint (which was not certified by peer review) is the author/funder, who has granted bioRxiv a license to display the preprint in perpetuity. It is made available under aCC-BY-NC-ND 4.0 International license.

\section{Fig. S3}

A

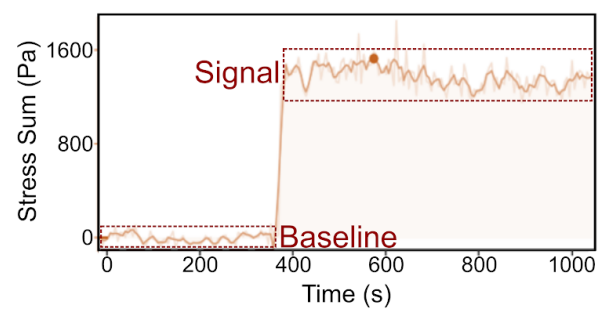

B

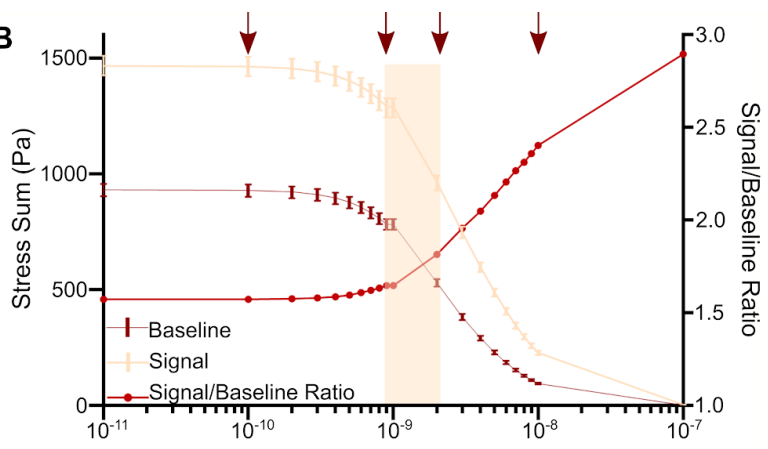

Regularization Factor
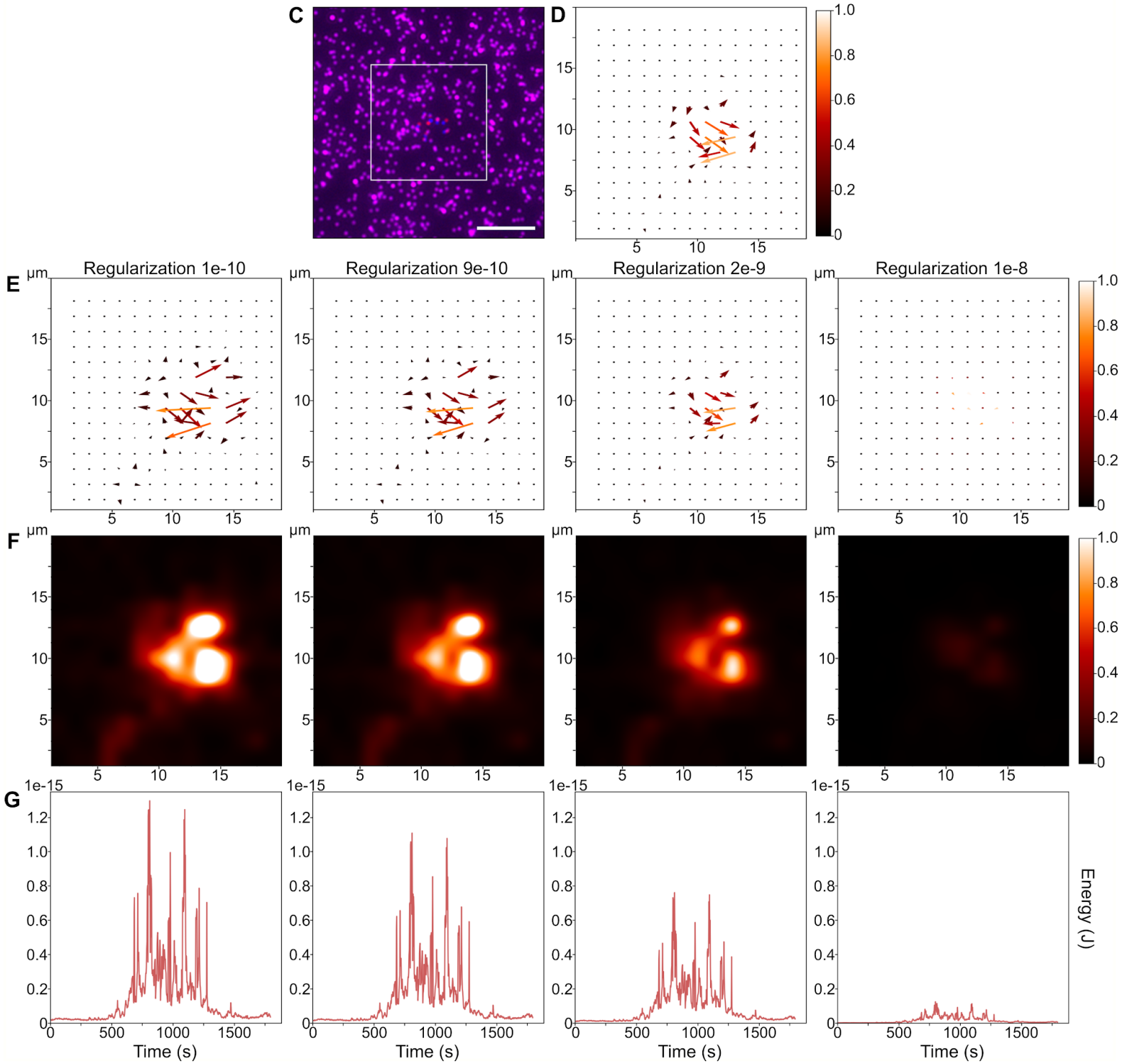
bioRxiv preprint doi: https://doi.org/10.1101/2022.02.11.480084; this version posted February 11,2022 . The copyright holder for this

preprint (which was not certified by peer review) is the author/funder, who has granted bioRxiv a license to display the preprint in perpetuity. It is made available under aCC-BY-NC-ND 4.0 International license.

\section{Fig. S4}
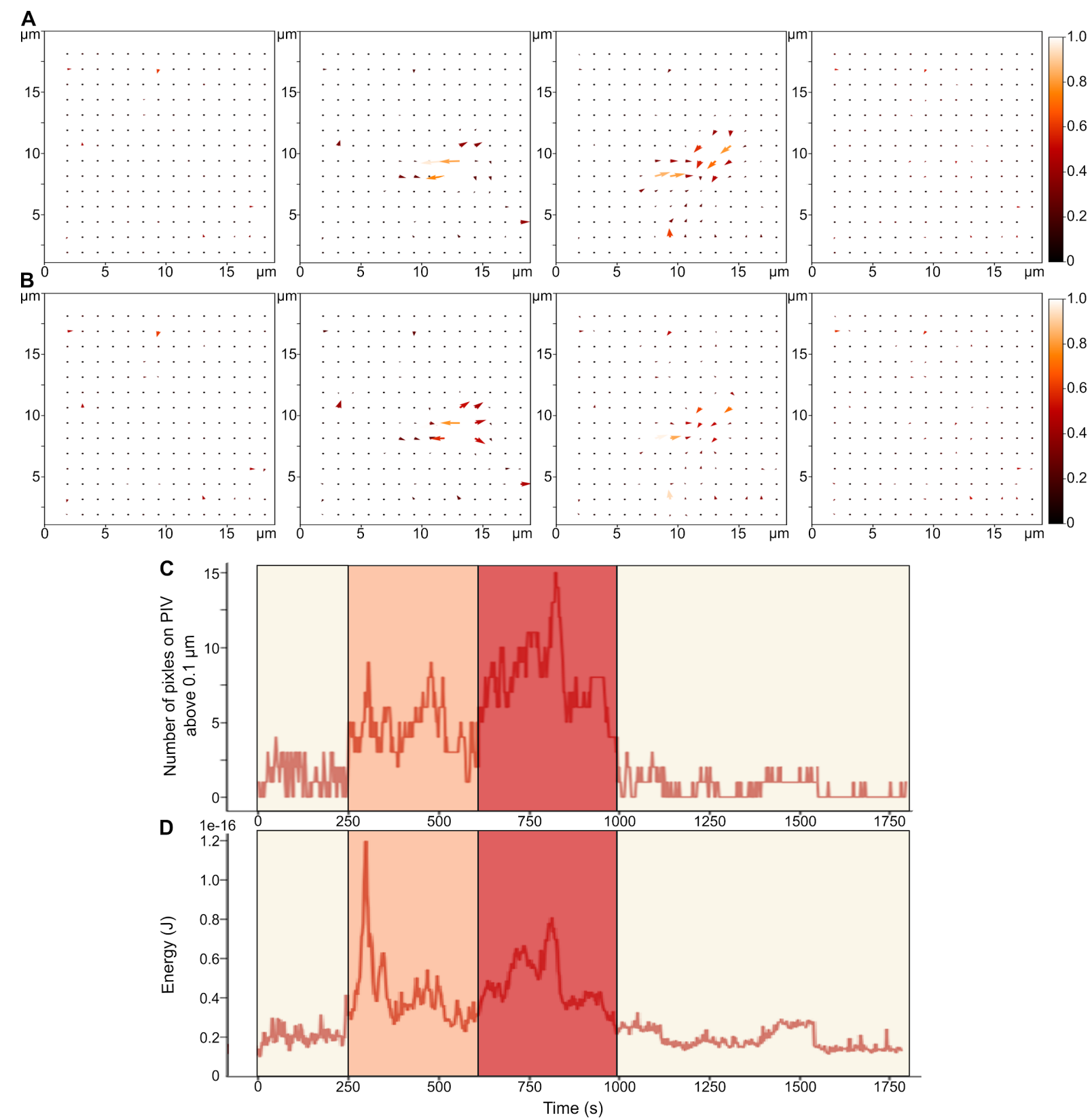